\title{
Role of regeneration in tissue repairing and therapies
}

\author{
Ravi Kant Upadhyay \\ Correspondence: rkupadhya@yahoo.com

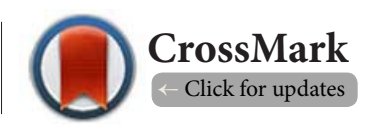

Department of Zoology, D D U Gorakhpur University, Gorakhpur 273009, India.

\begin{abstract}
Present review article emphasizes role of regeneration mechanism in various tissues and its use in organ transplantation for wound healing and repairing. This article also explains uses of various stem cell types in transplantation technologies and its applications in regenerative medicine and therapeutics. This review also addresses tissue engineering methods and use of new biological scaffold materials and promising candidates such as immunomodulators, adhesions, integrins in tissue repairing and induction of regeneration in injured tissues. In addition, role of various molecules of immune cell system, gene cascades and transcription specific proteins (TSPs) and growth factors in formation of microenvironment for differentiation are also explained. Moreover, mechanism of regeneration in various tissues such as neural, skeletal, cardiac, muscular, adipose and gonadial tissues, and bone marrow is described in detail. This article also suggest an urgent need for development of new advanced methods, technologies, biomatrices, polymers and scaffold materials, and cell based therapies to overcome the problem of disable and injured patients. Hence, landmark innovations are required in the field of regenerative medicine, tissue engineering, and developmental biology for successful tissue repairing and organ transplants to serve the human society.
\end{abstract}

Keywords: Stem cells, regenerative medicine, wound healing, organ transplants, cell replacement therapies

\section{Background}

Regenerative medicines belong to processes of creating living cells, replacing or regenerating human cells, tissues or organs. However, for repairing of age related effects, physical or biological injuries various biological and tissue engineering methods and stem cell therapies are used to restore the normal function (Figure 1). For phase specific tissue repairing, metabolites, factors and enzymes required in various pathways of self-sustained growth are selectively used. Moreover, for making tissue and organ transplantations successful few promising candidates such as immune-modulators, adhesions, integrins and new biological scaffold materials and bioactive molecules are essentially used to replace injured or missing tissues. However, after regeneration functional restoration of lost or damaged tissues and organs become possible [1] (Figure 2). It essentially needs a microenvironment or niche [2] for induction of regeneration because microenvironment affects and influences the cell behavior during development or phase of repairing [3]. Therefore, to minimize the risk of rejection of tissue and organ grafts; there remain a need of induction molecules for graft acceptance and tissue modification, remodeling, regeneration and replacement of tissues. However, various bio-molecules such as inducers, transcription factors, healers and molecules are essentially required for regeneration of cells which also assist growing new organs in vitro mainly in cell culture. Further, for repairing of injured organs and tissues stem cell based therapies and reprogramming of adult cells is being made by using pluripotent stem cells in vitro systems [4]. Induced pluripotent stem cells, commonly abbreviated as iPS cells or iPSCs are a type of pluripotent stem cell artificially derived from a non-pluripotent cell, typically an adult somatic cell. The successful induction of human iPSCs derived from dermal fibroblasts exhibit similar traits to those of embryonic stem cells (ESCs) but do not require the use of embryos. Some of the similarities between ESCs and iPSCs include pluripotency, morphology and self-renewal ability. In principle, regenerative medicines have many advantages and provided many options to clinical therapies. These involve use of stem cells mainly progenitor cells, transcription factors, biologically active molecules for immune-modulation, transplantation and induction of regeneration in vitro for developing organs and tissue grafts [5]. Thus stem cells are 
used to develop new organs for transplantation in cell culture systems [6]. These are proved highly useful in repairing of degenerated tissues, organ system failures and CNS diseases (Figure 2).
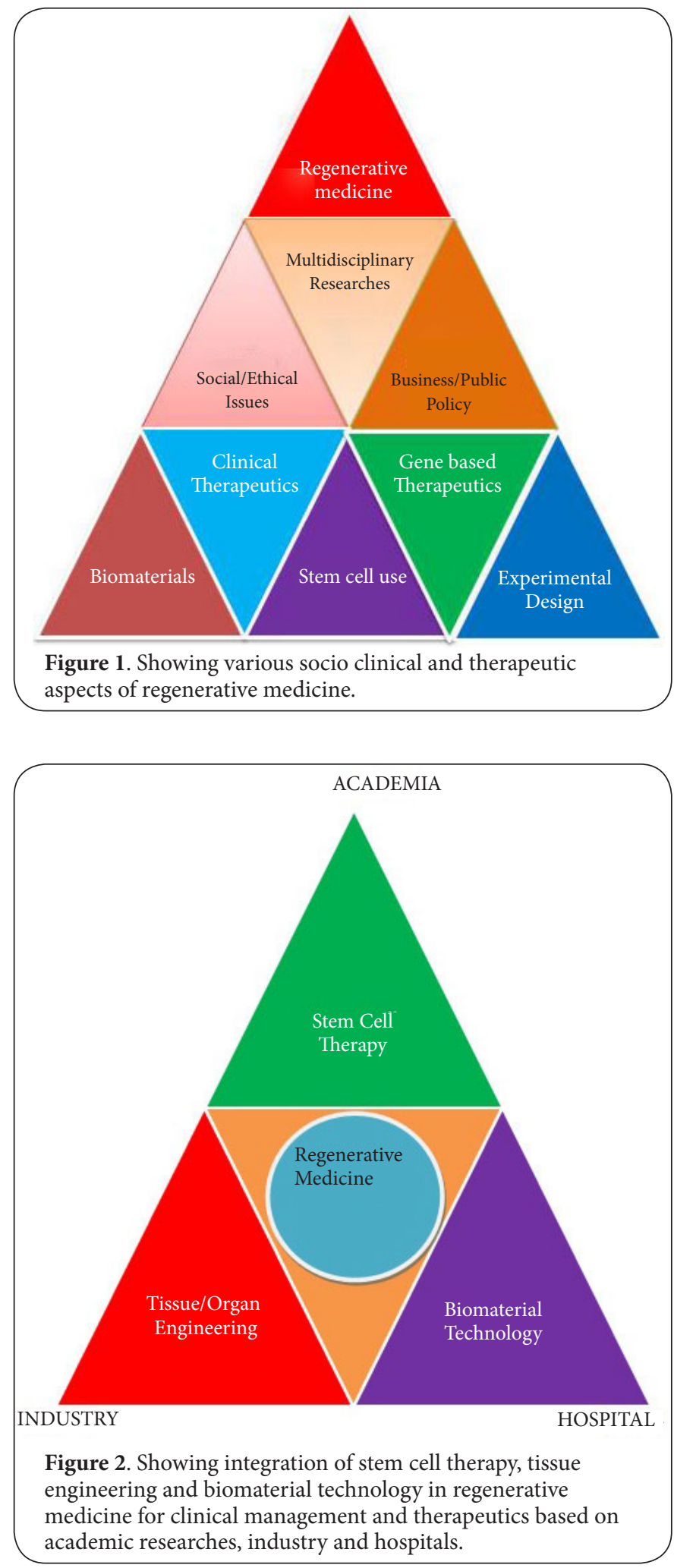

However, problem of shortage of organ transplants can be solved if patients own cells and tissues are used for regeneration in vitro. Thus use of proper factors could reduce the chance of rejection of organ transplants (Figures $3 \mathbf{a}$ and $\mathbf{3 b}$ ). However, to avoid the risk of graft rejection antigen modifications/improvements can be done for better immune selection. It is a most promising method to replace defective or damaged tissues or organs. In additions, by implanting stem cells progenitors lead to development of new stem cells that may enhance the body's own repair system. Moreover, clinicians can construct/regenerate small body parts from one or several cell types in the laboratory by using totipotent stem cells. However, disease specific source of cells or stem progenitors can be used various tissue therapies that may successfully change the course of chronic diseases (Figures $\mathbf{3} \mathbf{a}$ and $\mathbf{3 b}$ ). Regenerative medicines provide modern therapeutics mainly to enable tissue repairing, restoration of

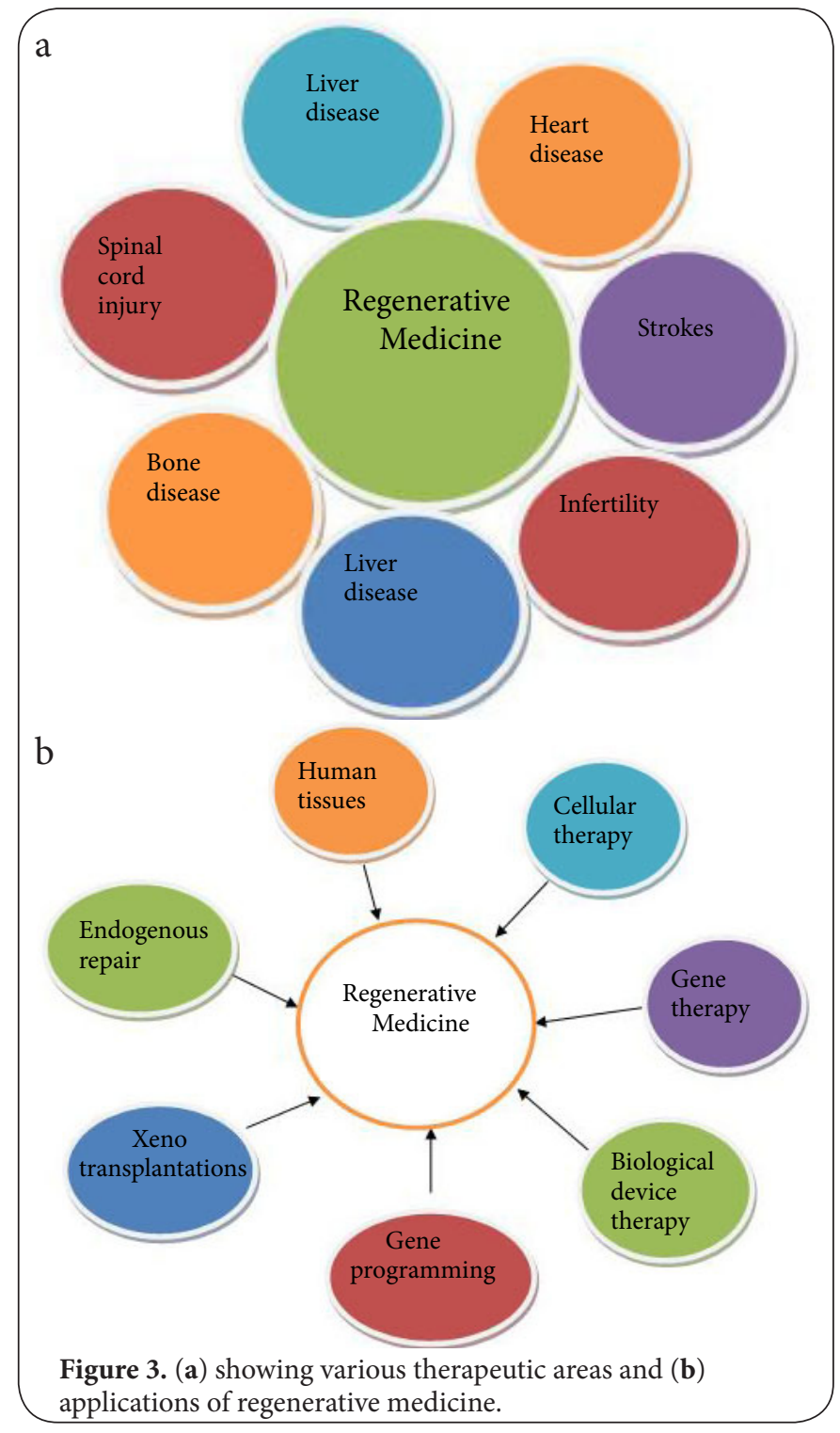


damaged or diseased cells or tissues (Figures $\mathbf{3 a}$ and $\mathbf{3 b}$ ). Thus, mutual benefits could thrive from cell therapies and tissue regeneration with the aid of developmental biology [7]. Present review article aims to explain role of regenerative medicine in cell therapies, wound healing, and regeneration of various tissue types such as tendon and ligament, cartilage, myocytes, heart muscles, thoracic, neurons, limbs, bone marrow, liver, kidney, trachobranchial, and gonadial tissues with special concern to role of various cells and its modifications in tissue engineering for organ repair.

\section{Review}

\section{Use in cell therapies}

However, for repairing of damaged tissues and organ system cell replacement therapy is used to induce growth and regeneration. Therefore, stem cells are used because they possess self-renewal property and can proliferate and differentiate into many cell types while normal cells do not possess this property [8]. Stem cells also show the ability to divide asymmetrically to form one daughter stem cell identical to it. This daughter cell show more restricted potential. Many stem cell divisions pass on symmetric and producing two stem cells which acquire potency only after differentiation. Thus, after regular mitotic divisions stem cells enlarge its population of differentiated cells to give rise normal cells. Similarly, cancerous cells generate large population of abnormal cells due to effect of carcinogens in microenvironment or gene mutations occurred in the genome. For example leukemia is a cancer of the white blood cells, which arise from differentiated white blood cells due to its transformation in a different cell types. However, two different cell types with different ability generate i.e., either leukemic tumor cells with unlimited growth, and few adult stem cells or its progenitors.

Tumor is a mixture of some cells capable of metastasis or seeding new tumors while some cells grow normally for a very limited time. It clears that a tumor possesses its own stem cells which can establish new tumor. More exceptionally, failures of programmed cell death can lead to uncontrolled cancerous growth which can be stopped by using anticancer molecules mainly proteins, cytokines, interferon and drugs. But controlling the cell death pathway and its regulatory signals can finish the tumor. Similarly, regulators of cell lineage, activation of cell cycle, and transformation of two similar daughter cells in two different cell types lead to development of functional differences [9]. Thus, new cell lineage different from parental cells starts due to genetic and environmental reasons during embryonic stages. Hence, new tumors cells raised place high nutritional requirements because of very higher catabolic rate than a normal cell and utilize large portion of body ATPs. It is the main reason that entire mechanism of cell division requires very high energy inputs and start catabolizing energy bearing molecules for various cellular functions. Thus, cancerous cell divide rapidly and raise a large population of abnormal cells, which circulate and adhere to new places and results in metastasis. At this stage it is very difficult to save the cells to become cancerous. Moreover, aged or defective, non-functional, or abnormal cells cannot stop programmed cell death. Though selective repairing of aged cells is possible if reprogramming is possible to send back them to achieve revitalization. But it is very difficult to revert the cancer cells into normal cells because most of the metabolic changes are irreversible in nature. Once structural changes, occur in various bio-molecules specifically lipid and protein conjugates, receptors, signaling molecules, factors and transcellular protein structures they cannot be reverted and restored for their normal functions.

However, cell lineage is patterned by the asymmetric distribution of key regulators to the daughter cells after a mitotic division. These regulators are external signals, which reach to the daughter cells. Asymmetric division occurs after polarization in cell that does localization and unequal distribution of cytoplasmic components. These components make pertinent differences in cell programming when they pass on to maturation. Thus healing of germ line cells is very difficult once they become cancerous due to effect of teratogens because, succeeding generation follow same cell lineage. There is a possibility that cell may adopt defective route, but in initial stages, such progenitor cells can be improved through reprogramming and will produce normal oocytes and sperms. However, in normal condition cell programming remain unaltered and cells follow a particular pattern for fixing cellular determinants during differentiation. These cells become quite distinct from the somatic cells but follow the path of somatic cell lineage, germ line and remain as stem cells. Stem cells have wider application in regeneration and are used in cell replacement therapy [10]. These cells much able do repairing of dilapidating spinal cord injuries and regeneration of neurons, myelin sheath and nerve cells. These are also used for drug testing in vitro system [11].

However, for repairing CNS virus generated and peripheral trauma injuries bioengineering grafts are transplanted by using tissue-engineering methods [12]. Similarly, adult stem cells can be used as an ideal alternative of Schwann cells (SCs) that are transplantable cells in bio artificial nerve grafts. Interestingly, adipose tissue has proven one of the most primary ASCs that can be used in nerve repairing [12]. These primary ASCs are easily obtainable and rapidly expanding cells which display low immunogenicity and differentiate into stem cells in vitro [12]. Stem cells are used in cardiac therapy for repairing heart muscles after a heart attack and in cognitive heart failures. These are also used for cell replacement therapy in neurological diseases. Similarly, stem cells are implanted in pancreas to replace degenerated insulin secreting cells by using insect cells. Stem cells are also used to grown in vitro organs for transplantation purposes by programming and redefining its functions [13]. However, various cell types of stem cells such as multipotent, pluripotent and totipotent have wider therapeutic applications and are used in organ transplants. 
Ravi Kant Upadhyay, Journal of Regenerative Medicine \& Tissue Engineering 2015,

Interestingly, UCB stem cells can be collected after birth from cord blood and epithelial tissues. These stem cells can be used for generation of various cell types and tissues in vitro. These are also used in cell and organ therapies mainly to replace defective, damaged or diseased organs. More often, use of UCB transplants do not need donor matching and reduces legal, economic and social burdens because they hinder and delay organ transplantations. UCB stem cells are used as an alternative to bone marrow transplants which result in lower incidence of graft rejection and other transplant complications. Furthermore, UCB derived HSCs are mainly used for transplantation for treatment of blood vascular [14] and neurological disorders. Though, it is very critical for making UCB banking establishments because very insufficient quantity of HSCs occurs in each Cord blood unit. Therefore, efficient expansion methods are to be needed to maintain stem cell characteristics of CD34 (+) CD38 (-) cells) [15] CD34(+) CD38(-) cells). Thus, formation of various cell types from UCB stem cells can overcome the problem of non availability of requisite number of cord blood cells for improvement of the stem cell transplantations. Further, role of certain transcription factors like Wnt 1 in new culture methods play important role in stimulating hematopoietic stem/progenitor cells expansion. It will offer a new therapeutic avenue for cord blood transplantations and open new gateway for regenerative medicine, stem cell banking and other clinical applications in future [15]. With this use of MSCs in regenerative medicine will widen, and more organ transplantations become possible for treatment of autoimmune diseases and disorders [16]. No doubt, self-renewal and differentiation of stem cells has great potential use in tissue healing and in cell replacement therapies [10]. Thus, new innovations are needed to solve fundamental problems associated with cell-cycle progression, tissue specification, organ homeostasis, and tumorigenesis [17].

\section{Teratomas}

Teratomas consist of disorganized tissues derived either from three embryonic germ layers or one germ cell layer occasionally. They show a remarkable degree of organization containing whole organs or form an encapsulated tumor inside an organ or surface of tissue. Pathologically teratomas are tumors, diagnosed by histological methods and named as non-seminomatous germ cell tumors. These are resulted from abnormal development of pluripotent stem cells, germ cells and embryonic cells. Teratomas are formed as a cell mass quite different from surrounding tissues and become highly disparate. Histologically mature teratoma is a solid or cystic mass that is formed both in hard and soft tissues such as skin, muscle, and bone. In few cases when skin surround a cyst and grow from the lower side of hair form a dermoid cyst and is derived from the ectoderm. Teratomas are generated after exposing the embryonic cells to the drug or due to effect of certain carcinogens or teratogens. Normally teratomas are formed in organs such as the brain, thyroid, liver, and lung but teratomas of hair, teeth, bone are formed very rarely. Most commonly these occur in soft organ tissues like eyes $[18,19]$, torso, $[20,21]$ and hands, feet, or other limbs [22]. These are also formed in the skull sutures, tongue, nose, cervical and coccyx. Similarly, Struma ovarii is a rare form of mature teratoma that contains mostly thyroid tissue. Teratomas of germ cell origin are known as gonadial teratomas which are usually formed in adult men and women, but they may also be found in children and infants. Encapsulated, teratomas are benign and become malignant and occur in several forms. In women mature teratoma occurs which becomes benign while in men it remains immature and is less malignant. Sometimes, these look like capsule or fluid-filled cysts either small or large that resembles a fetus. However cysts within mature teratoma are partially developed in organ systems mainly in cranial bones, long bones and a rudimentary beating heart $[12,13]$. In addition, embryonic origin or congenital teratomas also formed from germ cells. These are known as fetiform teratoma which is very rarely formed and resemble a malformed fetus upon maturation. Teratomas are highly painful and cause heart failures and hydrops of the fetus.

Ovarian teratomas do make torsion of the ovary and causes severe abdominal or pelvic pain or irritation of its ligaments. It results in a multistage illness that progresses from psychosis, memory deficits, seizures, and language disintegration into a state of unresponsiveness with catatonic features associated with abnormal movements, autonomic and breathing instability [23]. Metastatic testicular teratomas also occur which form a palpable mass in the testis. Similarly, mature cystic teratoma $[\mathbf{2 4 , 2 5 ]}$ and squammouns cell carcinoma occurs in the ovary of young patients $[26,27]$ mainly during childhood and adolescence [28]. Besides, extra gonadial [29] and sacrococcygeal heart are rare forms of teratomas [30]. More exceptionally, malignant cervical teratoma [31], germ cell tumors [32] and malignant retrobulbar and intra cranial teratoma are more common in child and adolescence stages [33]. Similarly, mediastinal teratomas often cause compression of the lungs, chock airways and cause severe chest pain and/ or respiratory tract. These are small ones or appear later in life as sacrococcygeal teratoma (Altman types I, II, and III) and cervical (neck) teratoma.

\section{Stem cells therapy}

Stem cells are also used as drug delivery systems and can work as living carrier system to bring chemotherapeutic agents directly to the targeted cancerous cells. Stem cells are also used as cellular testing system for evaluation of pharmaceutical potential of various drugs, natural products and carcinogens and can replace traditional animal models that are used for drug testing. These have great application in pharmaceutical biology and toxicology researches [11]. Moreover, cell based drug induction mechanisms can be explored that may assist in drug development and clinical therapeutics. There are many stem cell types based on their origin and renewal property. 


\section{Unipotent stem cells}

Unipotent stem cells divide to form a copy of it and form only one cell type or start one cell lineage and show self renewal property. These are quite different from non-stem cells or progenitor cells like muscle stem cell or any other cell types. For example, intestinal stem cells form their own cells and also form intestinal epithelium. These cells show restriction to develop other cell types and are therapeutically less usable in comparison to totipotent and pluripotent stem cells. These cells mostly occur in adult tissues and show a very limited ability to differentiate relative to other stem cells such as pluripotent, totipotent or multipotent cells. Despite their limited differentiation potential, unipotent cells have vast therapeutic potential to treat injuries and diseases due to their ability to self-renewal (Figures $\mathbf{4 a}$ and $\mathbf{4 d}$ ). Due to its proliferation property, or dividing repeatedly unipotent stem cells are used to generate healthy and viable cells for transplant purposes. For example, skin cells formed from epithelium are one of the most abundant types of unipotent stem cells. The epithelium is the outermost tissue layer, which in itself has a top layer of dead squamous epithelial cells. This is quite similar to the mucus membranes that line our mouths and other body cavities. However, for therapeutic purposes fresh viable cells or patient's own undamaged skin stem cells can be used for generation of sheets of cells for transplantation purposes over burned body surface area of the patient's. Thus, unipotent stem cells have immense use in therapeutics of burn injuries.

\section{Totipotent stem cells}

Totipotent stem cells are master cells because they can give rise to many specialized cell types (216) in the body except human body and placenta. A fertilized egg or zygote is a totiptoent cell because it shows capability to generate all the cell types of body. But it is not a complete stem cell because it lacks of self renewal, though it give rise different cells. Totipotent cells can also differentiate into extra embryonic stem cells and rarely exhibit totipotency and show pluripotency [34]. Though, it is true that embryonic stem cells can form any of the specialized cell types but never these turn into extra-embryonic cells of the placenta. Totipotent primitive stem cells occur in major organs like the stomach, intestine, pancreas and kidney. Normally totipotent cells are generated in human embryos at $72 \mathrm{hr}$. stage of development at 16 cell stage. Similarly, induced iPS circulating in the blood [35] also exhibit totipotency [34]. These cells also occur in different organs and show their presence as primitive cells. Artificially adult cells can be reprogrammed inside the body of animals to make them totipotent stem cells. These could be derived in the laboratory and form various tissues in artificial medium [36].
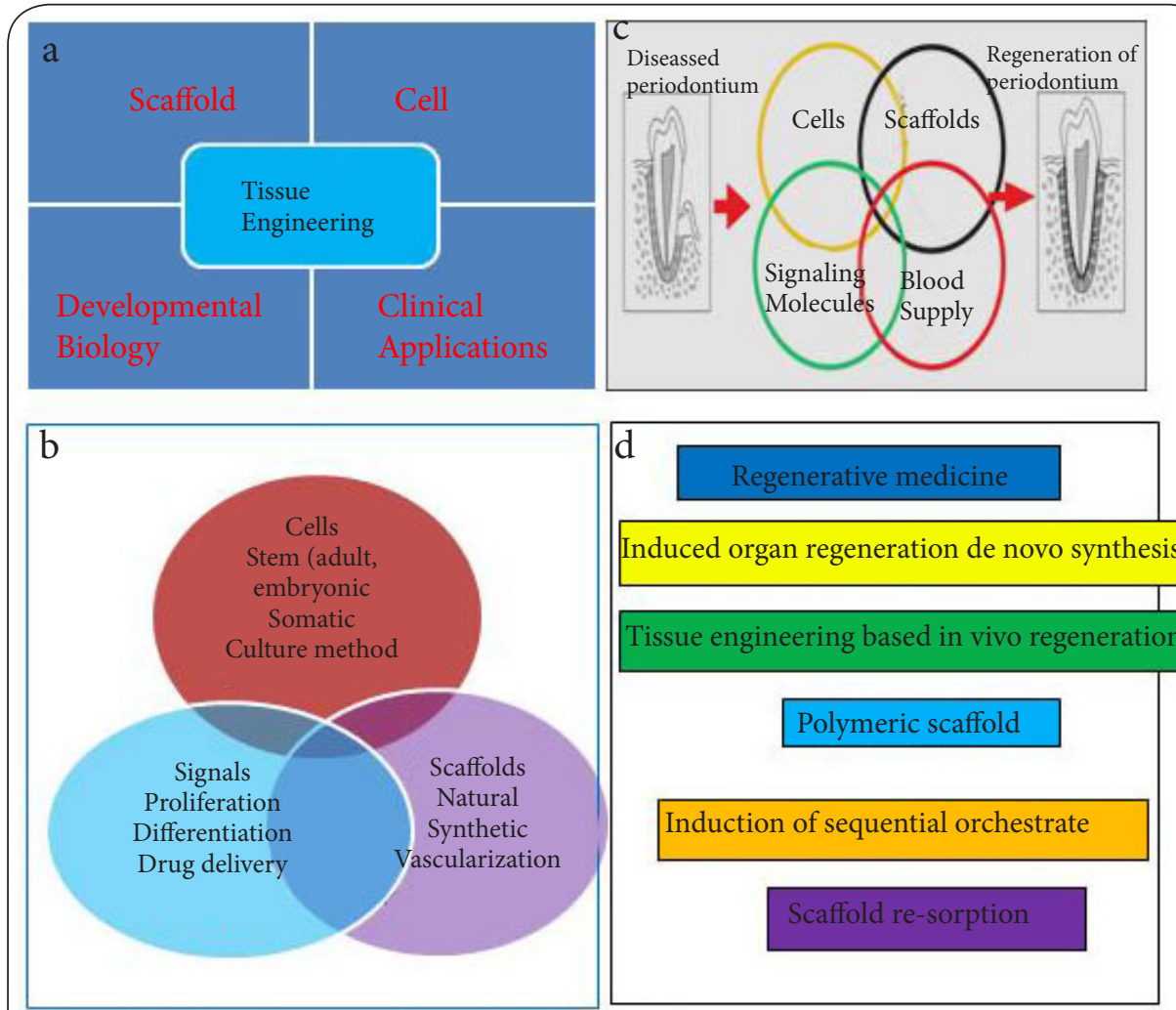

Figure 4. Showing important socio-clinical needs fulfilled by regenerative medicine (a) areas of tissue engineering (b) Regeneration of periodontium (c) coordination of cells, signals and scaffolds used (d) events followed in regenerative medicine. 
Ravi Kant Upadhyay, Journal of Regenerative Medicine \& Tissue Engineering 2015,

http://www.hoajonline.com/journals/pdf/2050-1218-4-1.pdf

doi: $10.7243 / 2050-1218-4-1$

Upon induction these cells form an embryo like structure after injected in the mice. Similarly, umbilical cord blood cells may form many other cell types which can develop into different organs mainly bone marrow. But it is an important question that how totipotency is regulated before finding its way towards pluripotency even after epigenetic state of totipotent cells [37].

\section{Pluripotent stem cells}

Pluripotent stem cells (PSCs) also known as multipotent which show the capacity of generating a number of different cell types or multiple blood cell types but never generate one specific cell type like skin cells. These are also known as somatic and germ line stem cells, and occur in children, as well as adults [18]. PSCs are highly specialized versatile cells that can give rise specialized cell type in the body except cells needed for development of fetus. These stem cells are rare and generally found small in number. PSCs reside in a number of tissues like umbilical cord blood [19] and bone marrow. These are one of the rich sources of adult stem cells [20] and are used in treating several conditions including spinal cord injury [21], liver cirrhosis, [22] chronic limb ischemia [38] and end stage heart failure [39]. The bone marrow stem cell quantity has been found to be declining with age in reproductive age group of females. Relatively it occurs lesser in males of same age group of females [23]. In animal models, pluripotent stem cells are directly generated from adult fibroblast cultures. However, for obtaining adult stem cells it does not require the destruction of an embryo.

Pluripotent stem cells are of large clinical importance and are used for development of cell based regenerative therapy for patients suffering from various diseases such as tumor formation [40]. These cells are lineage-restricted and are recognized by its tissue origin type i.e., mesenchymal stem cell, adipose-derived stem cell, endothelial stem cell and dental pulp stem cell $[\mathbf{4 1 , 4 2 ]}$. More specifically, human pluripotent stem cells (PSCs) offer enormous opportunities for regenerative medicine [40] and other biological applications [4]. Adult stem cells are also successfully used to treat leukemia and related bone/blood cancers through bone marrow transplants. PSCs are also found capable of producing hepatocytes and eventually form enamel (ectoderm), dentin, periodontal ligament, blood vessels, dental pulp, nervous tissues, and different end organs [43]. Moreover, adult mesenchymal stem cells are used in human [44] and veterinary regenerative medicine to treat tendon and ligament injuries [45].

Pluripotent stem cells show importance in translational research mainly in somatic epigenomics [46].Therefore, applying programming by using combination of transcription factors, a normal cell can be change into a pluripotent stem cell [40]. Few other factors such as DNA methylation, histone modification, post-transcriptional regulation by micro-RNAs and dozens of small molecules also play important role in epigenetic configuration [40]. These factor and molecules are also used in pluripotency reprogramming [40]. Thus, induced pluripotent stem cells are generated by ectopic expression of defined transcription factors in somatic cells, which can potentially provide unlimited self autologous cells for cell therapy [35]. Similarly, UCBMC-derived iPSCs (UCB-iPSCs) have identical characteristics to become pluripotent human embryonic stem cells (hESCs) that could accelerate the development of cell-based regenerative therapy for patients suffering from various diseases [40]. Hence, for generation of human iPSCs from UCBMCs dox-inducible lentiviral system requires four Yamanaka factors. Interestingly, iPSCs obtained from immunologically immature newborn umbilical cord blood mononuclear cells (UCBMCs) is of great significance in regenerative medicine [40].

Interestingly, disease targeting iPSCs are also generated which have important role in regenerative medicine. These could help in disease modeling, clinical treatment for development of therapies for tumorogenicity, immunogenicity and genomic instability [35]. However, to obtain target specific cells for regenerative medicine cellular reprogramming of human peripheral blood cells is highly needful [47]. Though it is very difficult to achieve, but conversion of UCB blood cells into therapeutic cells such as mesenchymal, neural, peripheral blood stem cells or HPSc is possible both in vitro and in vivo [47]. Therefore, for generating induced pluripotent stem cells (iPSCs) peripheral blood or blood mononuclear cells are used. Because a rare population of quiescent hematopoietic stem cells [48] maintains blood homeostasis, hence, hematopoietic stem cells if develop from a specialized subpopulation of endothelial cells would be of immense therapeutic applications [49]. More often, endothelial progenitor cells (EPCs) promote angiogenesis, which can be used in clinical trials of autologous EPC-based therapy. It may be more effective in treatment of vascular diseases [50] because EPC dysfunction of vascular disease (SS/Mcwi rat) exhibits impaired angiogenesis. Moreover, screening and neutralization of cell surface proteins that 'tag' and impair EPC function may provide an alternative approach to utilizing incompetent EPCs in greater numbers, as circulating EPCs are depleted in patients having vascular diseases. Such novel methods may be targets for repair of EPCS by using upgraded technologies. Certainly use of EPCs and iPSCs will do major advancement in the field of regenerative medicine [50].

Moreover, gene targeting in human pluripotent stem cells (hPSCs) has proven extremely difficult. For this purpose an efficient genome manipulation technology is followed by using RNA-guided DNase Cas9. This clustered and regularly interspaced short palindromic repeats (CRISPR) system is found highly efficient and useful for genome engineering of human iPS cells [51]. However, to obtain organotypic cells pluripotent stem cells can be selected on the basis of expressing green fluorescent protein and puromycin resistance under control of the Oct4 promoter. Moreover, OCT4-expressing cells in diffe-rentiation showed two attractors of pluripotency 
with different characteristics [52]. Further, persistence of potentially pluripotent cells was independent of supportive cells in embryoid body in culture (EBs). Because of their combined abilities of unlimited expansion and pluripotency, embryonic stem cells remain a theoretically potential source for regenerative medicine and tissue replacement after injury or disease [53]. Thus, induced pluripotent stem cell lines can derive from human somatic cells [54] mainly from adult mouse liver and stomach [55]. IPSc could also generate from brain, human testes [56] and adult fibroblast cultures in presence of certain defined factors [57].

\section{Hematopoietic stem cells}

HSCs are pluripotent stem cells that reside in the bone marrow of adult animals $[18,20]$. These form two lineages myeloid and lymphoid progenitors and both are capable of self-renewal. These act as both stem cells and precursor cells. HSCs generate numerous extracellular growth factors known as cytokines which regulate proliferation and differentiation of the precursor cells for various cell lineages. Similarly, cytokines required for repairing cellular injuries and more separate immune cell types could be generated. For example erythropoietin is generated from HSCs that induce formation of erythrocytes. This not only acts as an erythrocyte precursor but also activates different intercellular signal transduction pathways. Similarly, another cytokine GM-CSF stimulates production of granulocyes, macrophages, eosinophils and megakaryocytes. More specifically, in tissue transplants both GM-CSF and BFU-E activate production of terminally differentiated cells, which show unique combination of cell surface protein. Moreover, activation of the Hoxb4 gene in embryonic stem cells induces formation of hematopoietic stem cells while Bmi gene is needed for self-renewal of HSCs.

(HSCs) develop from a specialized subpopulation of endothelial cells known as hemogenic endothelium (HE). HSCs development takes place under certain signaling pathways which are maintained by certain biomolecules and activation factors. Activation of retinoic acid (RA) signaling in aorta-gonad-mesonephros-derived HE increase HSC potential, whereas conditional inactivation of the RA metabolizing enzyme retinal dehydrogenase 2 in VE-cadherin expressing endothelial cells in vivo abrogated HSC development. Wnt signaling completely blocked the HSC inductive effects of RA modulators, whereas inhibition of the pathway promoted the development of HSCs in the absence of RA signaling. Moreover, both RA and Wnt signaling are key regulators of HSC development. New molecular insights are needed for developing new strategies for generation of HSCs from pluripotent stem cells [49]. Like other body cells, HSCs also show ageing that leads to several functional changes which affect self-renewal and differentiation of cells [58]. All age-induced changes are intrinsic to HSCs but it is unknown that how does HSCs aging is driven by the acquisition of permanent genetic mutations. Though reversible, epigenetic component is a hallmark of HSC aging [58]. However, by employing induced pluripotent stem (iPS) cell reprogramming of aged hematopoietic progenitors all age related effects can be slow down that may provide longevity. These aged-derived iPS cells are allowed to reform hematopoiesis via blastocyst complementation. Similarly, iPS-derived HSCs are used for transplantation into new hosts to mitigate age related changes and diseases $[\mathbf{5 9}, \mathbf{6 0}]$.

\section{Mesenchymal stem cells}

Mesenchymal stem/stromal cells (MSCs) are multipotent stem/progenitor cells which showed high clinical application and are used in various cell therapies. MSCs form several specialized cell types but these are limited to particular organ or physiological system of origin. For example hematopoietic stem cells can produce many blood cells types in the circulatory system but cannot differentiate into neuronal cells or brain cells. MSCs are also derived from dental tissues [44]. However, several blood-vessel-derived precursor cell populations are isolated from multiple human organs that form bona fide MSCs. This vasculature serves as a systemic reservoir of MSC-like stem/progenitor cells. Moreover, identification and characterization of perivascular MSC precursors, including pericytes and adventitial cells is highly needful. Further, to know the functional roles of MSCs in vivo therapeutics few important cellular kinetics events such as cell adhesion, migration, engraftment, homing, and intercellular cross-talk during tissue repair and regeneration must be well known to figure dynamic regenerative processes [61]. MSCs express galectin- 9 which serves as an immune modulator interfering with multiple cell types including B cells. It may also serve as a predictive indicator for clinical MSCs therapy [16]. It is also essentially required to distinguish the therapeutic potency of MSCs derived from different donors and is strongly unregulated upon activation of cell by interferon $\gamma$ [16]. Similar to Gal-9 CaSr is also expressed in ovine fluid mesenchymal stem cells (oAFMSCs0) that makes calcimimectic $\mathrm{R}-568$ possible through activation on the mechanisms regulating osteogenesis in oAFMCSs which is highly useful in bone regenerative medicine [62]. Thus, calcium sensing receptor $G$ protein coupled receptor is identified that bind calcium ions and plays a physiological role in regulating bone metabolism. Further, 3D cultures are used to generate artificial tissues or organs in vitro model of solid tissues. It is an attractive approach that can revolutionize regenerative medicine because of more translational possibilities in grafting tissues [63].

MSCs differentiating in hematopoietic cells (HSC) maintain micro niche if these cells are implanted or injected into the damaged tissues these show regenerative properties. Due to their differentiation in multiple cells these cells are used in variety of therapeutic approaches [64]. Naturally, amniotic fluid maintains a specific cell niche from which many cell types are developed. These cell types have wider application in cell therapy mainly for bone marrow transplants and repairing 
Ravi Kant Upadhyay, Journal of Regenerative Medicine \& Tissue Engineering 2015,

of degenerate and damaged tissues [62]. Similarly, adipocyte cell lineage require specific cell niche that regulate stem cell differentiation. These cells promote the ability of stromal cells to support primitive hematopoietic cells in vitro [2]. Moreover, due to their self-renewal and differentiation properties MSCs are fundamentally associated with cell cycle progression to enable tissue specification, organ homeostasis and potentially tumorigenesis. It is determined by molecular interactions, coordinating fate choice and cell cycle progression. Moreover a FUCCI reporter system works in human pluripotent stem cells, during the progression of cell cycle. It is governed by cell cycle regulators cyclin D1-3a that control signals of TGF- $\beta$ Smad2/3 pathway. These mechanisms follow synchronizing differentiation during proliferation of developing tissues while cell cycle determines cell fate propensity [17].

\section{Embryonic stem cells}

Embryonic stem cells are pluripotent cells that can proliferate indefinitely in vitro and differentiate into cells of all three primary germ layers ectoderm, endoderm and mesoderm. Embryonic stem cells (ESCs) are totipotent, self-renewing, clonogenic and differentiate into a wide variety of cell types [65]. These cells are derived from mammalian embryos during the transition from totipotency, when individual blastomeres can make all cell lineages. More often, these cells differentiate into more than 200 cell types of the adult body when given sufficient and necessary stimulation for a specific cell type [66]. Embryonic stem (ES) cells are derived from the epiblast tissue of the inner cell mass of a blastocyst or earlier morula stage embryos (New Stem-Cell Procedure) [67]. These cells do not contribute to form the extra-embryonic membranes or the placenta. These cannot derive of neural stem cells from induced tissue-specific stem cells. But a cocktail of cytokines and small molecules, help to develop primitive neural stem (NS) cells derived from mouse ES cells and rat embryos [68]. Similarly, induced NS (iNS) cells can be generated from rat fibroblasts by forced expression of the transcriptional factors Oct4, Sox 2 and c-Myc and by using same set of cytokines and small molecules [68]. This unique property makes them exceptionally valuable for drug discovery and regenerative medicine. But it is very difficult to derive and culture ESCs.

More specifically, ES cells are pluripotent cells, which differentiate into many different cell types. They need highly specific microenvironments specific signals for correct and proper differentiation. Moreover, mouse embryonic stem cells ( $m E S$ ) or human embryonic stem cells ( $\mathrm{hES}$ ) both possess essential stem cell characteristics; require very different environments in order to maintain an undifferentiated state. CHIR99021 (CHIR) promotes selfrenewal and enhances the derivation efficiency of mouse (m)ESCs. Its downstream targets demonstrated that $\mathrm{CHIR}$ regulated genes in $\mathrm{mESC}$ not only influenced the $\mathrm{Wnt} / \beta$ catenin pathway by stabilizing $\beta$-catenin, but also modulated several other pluripotency-related signaling pathways such as
TGF- $\beta$, Notch and MAPK signaling pathways [69]. In addition, pluripotency-maintaining transcription factors are also up-regulated by CHIR regulated genes, while several development-related genes are down-regulated. $\mathrm{CHIR}$ also altered the expression of epigenetic regulatory genes and long intergenic non-coding RNAs [69].

Human ES cells grow on feeder layer of mouse embryonic fibroblasts (MEFs) and require basic fibroblast growth factor ( $\beta F G F$ or FGF-2) for proliferation [70]. Similarly mouse ES cells are grown on a layer of gelatin as an extracellular matrix for support and require presence of leukemia inhibitory factor (LIF). Both the stiffness of extracellular matrix (ECM) and surrounding niche/microenvironment play pivotal roles in ESC differentiation. Without optimal culture conditions or genetic manipulations embryonic stem cells rapidly differentiate in to other cells types [71] But it seems highly essential to understand the components which regulate ESC differentiation and unlock the regenerative potential of ESC-based therapies [65]. Stem cells isolated from blastocysts can be used for transplantation to find an option for the treatment of Parkinson, s disease and other neurodegenerative disease/disorder like Alzheimer disease. More specifically, after ablation of organ specific genes in stem cells knockout mice are developed.

Because of regenerative capability, embryonic stem cells (ES) show tremendous potential for treating myocardial infarction (death of myocardial tissue) and type 1 diabetes (death of pancreatic beta cells). These cells are maintained in presence of inhibitors of MEK and GSK3 (2i) which keep them in embryonically restricted ground state. However, heterogeneous expression of the extra embryonic endoderm marker Hex in 2i-cultured embryos, block 2i development prior to epiblast commitment [66]. These Single Hex-positive ESCs co-expressed epiblast and extra-embryonic genes contribute all lineages in chimeras. Similarly, cytokine LIF, was found necessary for ESC self-renewal, and it support the expansion of ESC population but did not directly support Nanog-positive epiblast-like ESCs. Similarly, 2i and LIF support a totipotent state in embryonic stem cell transplantation [69], in comparison to early embryonic cells that co express embryonic and extra embryonic determinants [66]. Embryonic stem cells derived from oligodendrocyte progenitor are used in cell transplants for restoration of locomotion after spinal cord injury because these cells remyelinate [72]. ESC culture and differentiation require cell specific niche/microenvironment [65]. Niche is also formed by spindle shaped cells found on the surface of bone in the bone marrow. Moreover, expression of tissue inhibitor of metalloproteinase-4 (TIMP4) in differentiating cells needs Matrix metalloproteinase-9 (MMP9) that induces fibrosis and causes stiffness of the ECM and impairs differentiation of cardiac stem cells into cardiomyocytes (Figure 6b) [65]. However, for clinical use various embryonic stem cell lines [73] have been derived from human blastocysts without destruction of human embryo [74,75]. These cell lines require expression of several transcription factors and cell surface proteins for 


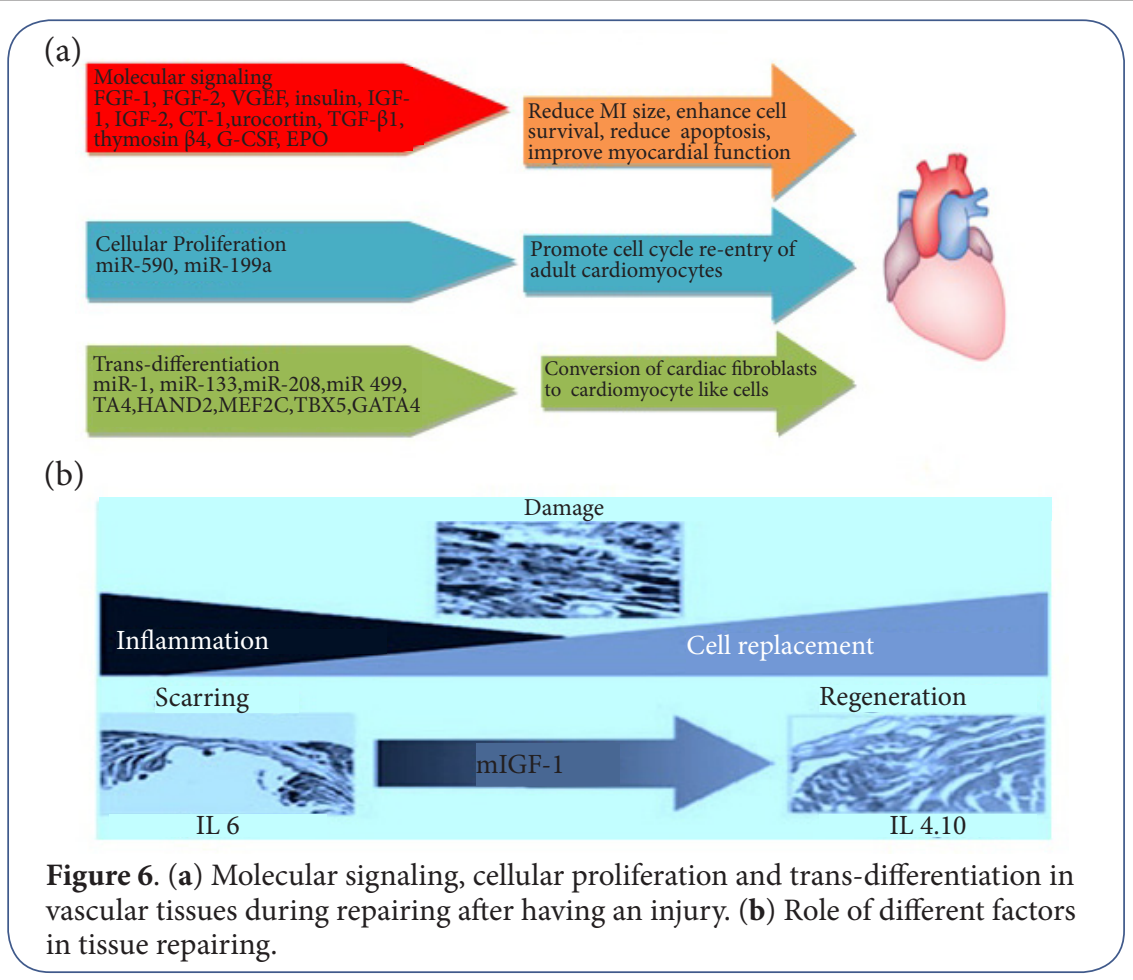

differentiation. ES cells are also derived from skin cells [76] and single hair cells [77] by using simple switch turns [78]. Activated embryonic stem cells can differentiate in to various cell types which show many therapeutic applications [75]. ES cells differentiation depend on the transcription factors such as Nanog, Soc2 and Oct 4 and need stepwise engineering and micro-environments for differentiation [79].Because transcription factors Oct-4, Nanog, and Sox2 form the core regulatory network that ensures the suppression of genes and lead to differentiation and the maintenance of pluripotency [80]. Stem cell includes many characteristic proteins, transcription and growth factors and programming inducers, many of them are still unknown [73]. The cell surface antigens most commonly used to identify hES cells are the glycolipids stage specific embryonic antigen 3 and 4 and the keratan sulfate antigens Tra-1-60 and Tra-1-81.

No doubt stem cell transplantation shows multiple and much wider applications in regenerative medicine. This is an emerging multidisciplinary field that focuses on the development of alternative therapies for tissue/organ repair and has wider application in bioengineering and medicine [5]. Tissue engineering is based on integrative approaches using scaffolds, cell population, growth factors, nano-medicine gene therapy and other techniques (Figures $\mathbf{5 a}$ and $\mathbf{5 b}$ ). It is a newly emerging science whose main objective is to induce the formation of new functional tissues, rather than implanting spare parts or organ transplants for replacement of diseased organs [5]. However, for regeneration of skeletal muscle functions tissue engineering muscle repair (TEMR) constituents are implanted [81]. For the same purpose, chitin is also found suitable scaffold material and highly useful matrices for tissue engineering, stem cell propagation and differentiation [82]. It is a polymer that has many applications in tissue engineering mainly in tissue repairing [82]. Similarly, fibroin is used as promising candidate for ligament tissue engineering [83]. Though sericin a protein from silkworm also possesses more over similar properties but due to biocompatibility reasons and generation of immune responses in the human body it has been kept out of use [83]. No doubt production of scaffolds structures of fibroin has wider application in TE and regenerative medicine.

\section{Therapeutic approaches}

Stem cells are highly useful in various therapies and show wider application in repairing of various tissues such as integument, skeletal, cardiac, muscular, neural, adipose and gonadial tissues (Figures $\mathbf{6 a}$ and $\mathbf{6 b}$ ). There are stem cell therapeutic methods that can replace defective body cells such tendon, cartilage [84] and improve local tissue defects [85]. Stem cells also help in dental cares by inducing regeneration or differentiation of dental epithelia into enamel-producing ameloblasts [86]. MSCs implanted in pancreas can replace defective islet beta cells, enhance $\beta$-cell proliferation [87], cure type 1 diabetes $[88]$ and do its reversal $[\mathbf{8 9}, \mathbf{9 0}, \mathbf{9 8 , 9 9}]$ in non-obese diabetic mice [91,92]. Similarly, implantation of multipotent stem cells implanted in bone marrow can suppress ovarian cancer and stop metastasis [90,92]. These are also implanted to remove incurable defects like tumors by counterbalance between mature BDNF and proBDNF factors that may regulate tumor growth $[\mathbf{8 8 , 9 3}]$. HSCs stem cell transplantation is used in 


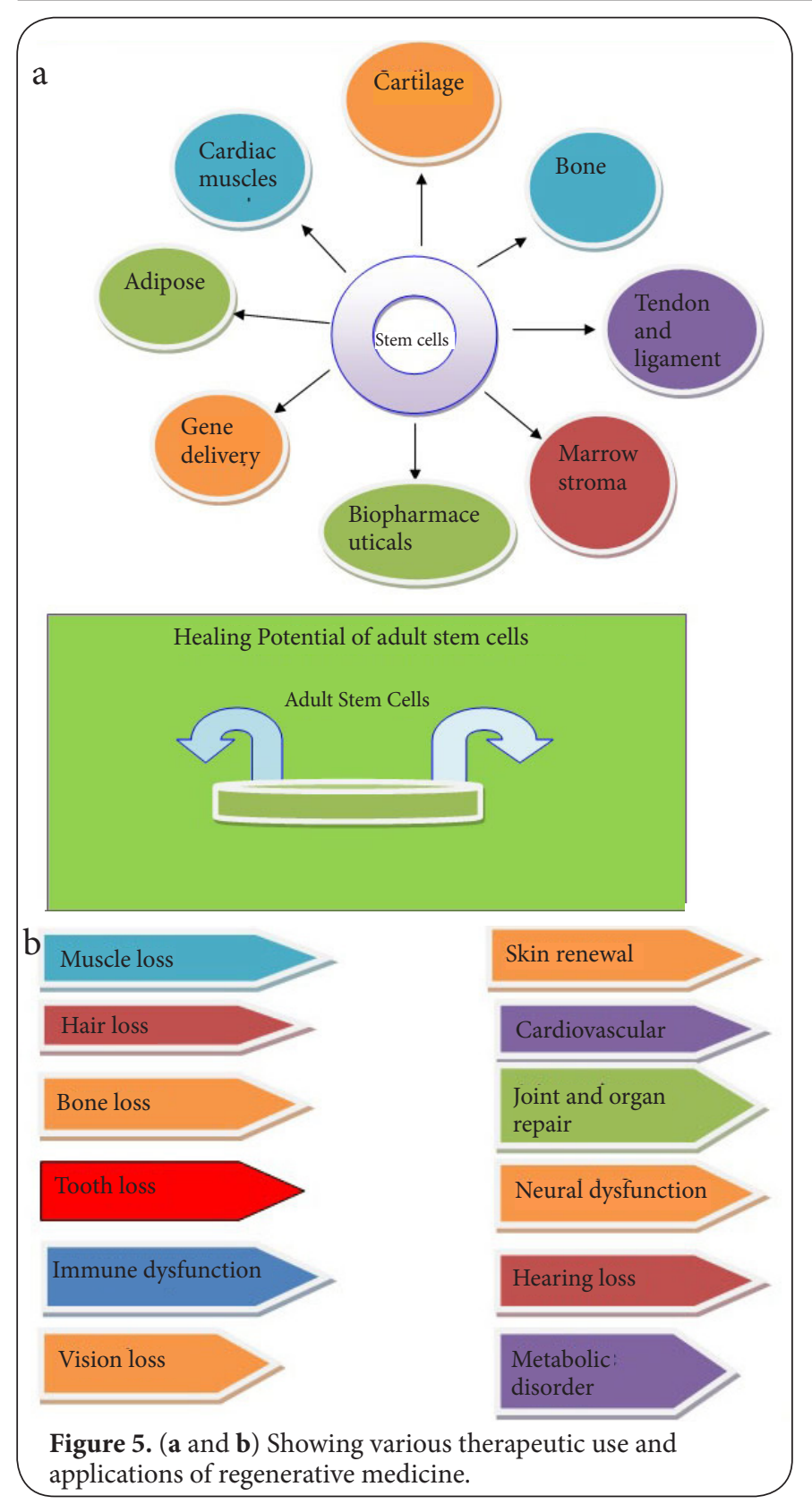

multiple myeloma $[\mathbf{9 4 , 9 6 ]}$. Endothelial cells (ECs) show wider therapeutic potential in cardiovascular [94,95], Parkinson's disease [95,96], and neurological diseases [97]. These cells do immune regulation of T lymphocyte cells $[93,98]$ and induce mitochondrial biogenesis in primary human endothelial cells (ECs) and in Akt3-null mice [89,99]. MSCs are used in regenerative medicine, for wound healing, tissue regeneration and transplantation of organs and therapeutic care of autoimmune diseases (Table 1).

\section{Hair follicle regeneration}

The hair follicle regeneration from follicular fragments and dissociated cells is an important area of research in clinical medicine and therapy. Follicle stem cells are potential source of hair regeneration [100]. Its trichogenic culture is maintained in vitro and follicle cells are subsequently delivered into the patient [100]. HFs is used as regenerative mini-organs that offer a highly informative model system to study the regulatory mechanisms of hair follicle stem cells (hfSCs) homeostasis and differentiation. However, BMP signaling play pivotal role in in hfSCs regulation and hair morphogenesis [101]. BMP signaling governs hfSCs quiescence in the bulge and differentiation of matrix progenitors that also distinguish non-overlapping function of $\mathrm{pSmad} 8$ with $\mathrm{pSmad} 1$ and $\mathrm{pSmad} 5$.

\section{Myo-epithelial regeneration}

Myoepithelial cells also show regeneration capacity but at a slower rate because of slow cycling occurred in several stem cells (SCs). The MCs are identified in adult tissues including hair follicle and cornea, in basal and luminal layers in sweat glands (SG). Similarly, label-retaining cells (LRCs) are localized in sweat glands. Its gene expression profile is determined SG LRCs and non-LRCs has been determined in vivo. Moreover, sweat gland stem cells (SGSCs) are important in SG homeostasis and as an alternative source of cells in wound healing and their plasticity for regenerating different skin appendages [101]. Similarly, several Bone Morphogenetic Protein (BMP) pathway genes to be up-regulated and confirmed a functional requirement for $B M P$ receptor $1 \mathrm{~A}$ (BMPR1A)-mediated signaling in SG formation (Figure 6a).

\section{Tracheobranchial regeneration}

Repairing of airway transplantation remains a major challenge in the fields of thoracic surgery and regenerative medicine. Five principal types of tracheobronchial substitutes, including synthetic prostheses, bioprostheses, allograft, auto grafts and bioengineered conduits are used for repairing of acute or chronic respiratory dysfunctions [6]. But none of these methods provided a standardized technique for the replacement of the airways. More recently, few clinical attempts have shown encouraging results with ex vivo or stem cell-based engineered airways and tracheal allograft implanted after heterotopic revascularization. Aortic grafts are used for extensive airway reconstruction as a biological matrix. Thus, in vivo regeneration of epithelium and cartilage could help in human tracheabronchial diseases [6]. Hence, new innovation are needed for development of novel prognostic, diagnostic, and treatment options that may provide major benefits for patients with acute or chronic respiratory dysfunction, cardiac-related disorders, esophageal problems, or other diseases in the thorax. Though, allogeneic organ transplants are also made but these could show very low rates of success because of its dependency on a very limited supply of donated organs [102]. Such organ transplants also require lifelong treatment with immunosuppressants, if these remain unavailable generate many adverse effects. Hence, bioengineered organs and tissues will be of wider clinical applications, but its routine 
Table 1. Various genes and factors which play important role in cell programming and regeneration.

\begin{tabular}{|c|c|c|c|}
\hline Gene/factors family & Action & Regulatory function & References \\
\hline Oct" family (Oct-3/4 Oct1 and Oct6), & Induction & $\begin{array}{l}\text { Crucial transcriptional } \\
\text { regulators }\end{array}$ & {$[52]$} \\
\hline Oct-4 $(+)$ & Pluripotency & Differentiation & {$[52,68]$} \\
\hline Sox gene family (Sox1, Sox2, Sox3, and Sox 15 ) & Induction & $\begin{array}{l}\text { Crucial transcriptional } \\
\text { regulators }\end{array}$ & {$[68]$} \\
\hline Klf family Klf1, Klf2, Klf4, and Klf5 & Transcription factors & Regulatory protein & {$[183]$} \\
\hline Myc family (c-myc, L-myc, and N-myc) & Protooncogenes & Induction of iPS cells & {$[68]$} \\
\hline Nanog & $\begin{array}{l}\text { Promoting } \\
\text { pluripotency }\end{array}$ & $\begin{array}{l}\text { Transcription regulatory } \\
\text { protein }\end{array}$ & {$[71,75]$} \\
\hline LIN28* & mRNA binding protein & Factor for iPSC generation, & {$[71,75]$} \\
\hline Glis1 & Transcription factor & Induce pluripotency. & {$[71]$} \\
\hline hESC & Pluripotency factor & Lineage differentiation & {$[40]$} \\
\hline $\begin{array}{l}\text { SSEA-3, SSEA-4, TRA-1-60, TRA-1-81, TRA-2- } \\
\text { 49/6E, and Nanog }\end{array}$ & & Markers specific to hESC & {$[50]$} \\
\hline SSEA-1, mESCs & Inducer & $\begin{array}{l}\text { Mouse embryonic stem cell } \\
\text { markers }\end{array}$ & {$[69]$} \\
\hline CHIR99021 & $\begin{array}{l}\text { Modulate TGF- } \beta \text {, Notch, MAPK } \\
\text { signaling pathways }\end{array}$ & $\begin{array}{l}\text { promotes self-renewal in } \\
(\mathrm{m}) \mathrm{ESCs}\end{array}$ & {$[69]$} \\
\hline $\begin{array}{l}\text { Oct-3/4, Sox2, Nanog, GDF3, REX1, FGF4, ESG1, } \\
\text { DPPA2, DPPA4, and hTERT }\end{array}$ & & iPSCs expressed genes & {$[80]$} \\
\hline GCF Cytokines & $\begin{array}{l}\text { Inflammation, cystic growth, and bone } \\
\text { resorption that characterize cystic } \\
\text { lesions }\end{array}$ & -- & {$[65]$} \\
\hline IL-3, GM.CSF, IL-6, & Granulocyte (Phagocytic immature cells) & $\begin{array}{l}\text { Monocyte Macrophage } \\
\text { precursos }\end{array}$ & {$[177]$} \\
\hline $\begin{array}{l}\text { HSC, IL-3 and IL- } 6 \text { alone hematopoietic growth } \\
\text { factors }\end{array}$ & & $\begin{array}{l}\text { Tntitumor agents for solid } \\
\text { tumors }\end{array}$ & {$[177]$} \\
\hline Epo-SCF, GMCSF, IL-3 & Erythropoietin receptor & $\begin{array}{l}\text { Erythrocyte progenitor } \\
\text { Markers }\end{array}$ & \\
\hline BMP TGFb & Signaling protein & $\begin{array}{l}\text { Mesenchymal cell } \\
\text { signaling pathways }\end{array}$ & {$[117]$} \\
\hline $\begin{array}{l}\text { BMP, FGF, Hedgehog, Notch, PDGF, Wnt, } \\
\text { periosteal-mediated bone regeneration }\end{array}$ & & Therapeutics & {$[117]$} \\
\hline cTnT, cTnI and $\mathrm{Cx} 43$ & Transcription factors & $\begin{array}{l}\text { Cardiac regenerative } \\
\text { medicine }\end{array}$ & {$[142,143]$} \\
\hline bHLH & $\begin{array}{l}\text { Trancription factors MyoD, myogenin, } \\
\text { Myf5 and MRF4 }\end{array}$ & Muscle regulator factors & {$[131,132]$} \\
\hline $\begin{array}{l}\text { Drosophila BCL6 homolog Ken and Barbie } \\
\text { promotes somatic stem cell self-renewal in } \\
\text { the testis niche }\end{array}$ & -- & -- & {$[169]$} \\
\hline Let-7-Imp axis & Regulates aeging of Drosophila & Testis stem cell niche & {$[174]$} \\
\hline Calcimimectic & $\begin{array}{l}\text { R-568 regulating osteogenesis in } \\
\text { oAFMCSs }\end{array}$ & $\begin{array}{l}\text { Promote bone } \\
\text { regeneration }\end{array}$ & {$[62]$} \\
\hline cyclin D1-3 & control TGF-b Smad $2 / 3$ pathway & $\begin{array}{l}\text { proliferation of developing } \\
\text { tissues }\end{array}$ & {$[17]$} \\
\hline pSmad8 with pSmad 1 and pSmad5 & BMP signaling hfSCs regulation & Hair morphogenesis & {$[101]$} \\
\hline $\begin{array}{l}\text { Brain-derived neurotrophic factor (BDNP)/TrkB } \\
\text { signaling }\end{array}$ & $\begin{array}{l}\text { Effectuate information processing, learn- } \\
\text { ing, and memory }\end{array}$ & & {$[88]$} \\
\hline Pax3 & Transcription factor & $\begin{array}{l}\text { Alveolar } \\
\text { rhabdomyosarcoma }\end{array}$ & \\
\hline
\end{tabular}


Ravi Kant Upadhyay, Journal of Regenerative Medicine \& Tissue Engineering 2015,

http://www.hoajonline.com/journals/pdf/2050-1218-4-1.pdf

Continuation of Table 1.

\begin{tabular}{|c|c|c|c|}
\hline Gene/factors family & Gene/factors family & Regulatory function & References \\
\hline $\begin{array}{l}\text { SF/HGF Scator factor - paracrine cellular growth, } \\
\text { motility and morphogenic factor, promotes } \\
\text { proliferation, adhesion and survival of human } \\
\text { human hematopoietic progenitor cells (CD34+) }\end{array}$ & HPCs & $\begin{array}{l}\text { paracrine cellular growth, } \\
\text { motility and morphogenic } \\
\text { factor, promotes prolifera- } \\
\text { tion, adhesion and survival } \\
\text { of human human hemat- } \\
\text { opoietic progenitor cells } \\
\text { (CD34+) }\end{array}$ & {$[59,60]$} \\
\hline GDNF TGF- $\beta$ Hedgehpg & Facilitates maturation & Mesenchymal stem cell & {$[163]$} \\
\hline Transfering growth factor a (TGF a) & Cytokine growth & development, inflammation & \\
\hline VEGF Vascular endothelial growth factor (VEGF) & $\begin{array}{l}\text { signal protein stimulates vasculogenesis } \\
\text { and angiogenesis }\end{array}$ & & {$[147]$} \\
\hline
\end{tabular}

${ }^{\star}$ Expressed in embryonic stem cells and embryonic carcinoma cells associated with differentiation and proliferation. ${ }^{* \star}$ Glis 1 is transcription factor that can be used with Oct-3/4, Sox 2 and Klf4 to induce pluripotency. It poses numerous advantages when used instead of C-myc. ${ }^{\star}$ MRFs associate with E2A and MEFs to form large transcriptional complexes that drive myogenesis and muscle specific genes. ${ }^{*} 17$ genes in the KLF family.

implementation is still very difficult. Hence, biological and synthetic solutions, introduction of novel strategies and technologies are required for clinical treatment of disease and disables. Though, ethical challenges still persist which hinder further progress of this innovative research area [102].

\section{Neural stem cells generation from fibroblasts}

Stem cells have great importance in the formation of the neurons and ways to prevent neuro-degeneration. These cells divide to form daughter stem cells, one remain stem cell and another form neuroblasts. Similarly, a neuroblast generates two daughter cells, one a neuron and one a glial cell. As most of the mammalian brain cells stop dividing by adulthood but stem cells in the one part of brain (sub ventricular zone) continue to act as stem cells and generate new neurons. More specifically, SVZ neural stem cells become astrocytes a type of glial cell. Neural stem cells also possess the potency of astrocytes and generate glial fibrillar acidic protein (GFAP). Like other cells neural stem cells divide in a microenvironment that essentially need use of blend of factors such as FGF, BMPs, IGF, VEGF, TGF alpha, and BDNF. Similarly, by using a cocktail of cytokines and small molecules, induced NS (iNS) cells can be generated from rat fibroblasts by forced expression of the transcriptional factors Oct4, Sox 2 and c-Myc. Thus, generation and long-term maintenance of iNS cells is also possible that may require highly specific transcriptional, translational and growth factors for maintaining microenvironment [103].Moreover, direct conversion of fibroblasts to functional neurons is also possible in presence of certain defined factors [103] (Table 1).

\section{Wound healing}

Wound healing is a complex and dynamic process of replacing devitalized and missing cellular structures and tissue layers [104]. Normally, this process completes in 3 or 4 distinct phases i.e., inflammatory, fibroblastic, and maturation [3]. Earlier these phases were recognized as inflammatory, proliferative, and phase of remodeling [105]. Now these have been reestablished as homeostasis, inflammatory, proliferative or granulation, and remodeling or maturation phase $[\mathbf{1}, \mathbf{1 0 6}]$. Moreover, wound healing contain broad phases, which operate through complex and coordinated series of events that includes chemotaxis, phagocytosis, neocollagenesis, collagen degradation, and collagen remodeling. In addition, angiogenesis, epithelization, and the production of new glycosaminoglycans (GAGs) and proteoglycans vital conjugates form wound healing milieu that plays important role. However, application of new therapeutics may promote wound healing in patients suffering from chronic skin wounds [107]. Moreover, it was also observed that skin of amphibians possesses a remarkable regenerative capacity that can be used for clinical studies. Skin cells are grown and allow regeneration of organ system in culture that will help in exploration of the effects of amphibian skin-derived agents on re-epithelialisation both in frog and human skin. In this system thyrotropin-releasing hormone (TRH) acts as a novel stimulant of epidermal regeneration and show similar effects. TRH also stimulates wound closure and formation of neo-epidermis in organ-cultured human skin, accompanied by increased keratinocyte proliferation and wound healing-associated differentiation and work as a neuroendocrine wound repair promoter [107]. More often, functional recovery of spinal cord injury is also healing up by using intra-lesional bone marrow mononuclear cells embedded in polymer scaffold [21] (Figures 6a and 6b) (Table 1).

\section{Tendon and ligament regeneration}

As dense connective tissues bone is found to connect either to a muscle or to a bone respectively. Similarly, tendon and ligament (T/L) arise from the somatic mesoderm [108]. There are many challenges in restoring $T / L$ function following an 
injury include optimal combination of biological agents as well as their delivery to the injury site. It is only possible by identifying molecular mechanisms involved in $\mathrm{T} / \mathrm{L}$ development and natural healing of bones $[108,109]$. Further, tendon and ligament could couple with the capability of producing complex biomaterials to deliver multiple bio-factors with high spatiotemporal resolution and specificity. It will make regenerative procedures more closely recapitulate $T / L$ morphogenesis, and regeneration but it is not possible in simple tissue repair $[108,109]$. Moreover, few inductive signals from the adjacent sclerotome and myotome which up regulate expression of Scleraxis have been identified. Scleraxis is a key transcription factor which is recognized essential for tenogenic and ligamentogenic differentiation. Similarly, collagen fibers are ubiquitous macromolecular assemblies in nature, which form structures that support tensile mechanical loads within the human body [110]. Thus, aligned type I collagen fibers are considered more workable primary structural motif for tendon and ligament regeneration. More often regenerative approaches need easily proliferating cells, scaffold materials, bioactive agents, and mechanical stimulation to improve the natural healing response in injured tissues. These biomaterials due to their structure fabrication properties are considered more promising candidates for mediating regeneration of these tissues. Therefore, construction of complex and challenging biomaterials, may improve the mechanical function of tendons and ligaments. Further, potential for tailoring and manipulating the interactions between collagen fibers and biological systems, as hybrid biomaterialbiological assemblages, will help to develop novel tissue engineering strategies for tendon and ligament regeneration [110]. However, semitendinosus tendon can regenerate after being harvested in its whole length and thickness for anterior cruciate ligament $(\mathrm{ACL})$ reconstruction, but it is not applicable to make a neo-tendon. Hence both biologically and functionally these could be used for iterative ligament reconstruction [111] (Table 1).

\section{Cartilage regeneration}

Human cartilage progenitor cells show chondrogenic and proliferative potential and form elastic cartilage that needs long-term tissue maintenance. Moreover, ear derived cartilage progenitor cells are used to reconstruct hyaline cartilage which posseses different mechanical and histological properties [112]. This reconstructed cartilage rich in proteoglycans show unique histological properties to joint hyaline cartilage. It is highly useful for repairing of degenerative arthropathies [112]. But in vitro cartilage generation using primary cell sources is limited. Hence, to increase cell availability and expansion potential new repair technologies are highly demanded. But pluripotent stem cells show the capacity for chondrocytic differentiation whose extended expansion may provide potential solution to cell-based cartilage regeneration. More often, producing cartilage using adult and embryonic stem cells, and translation of these technologies to the clinics seems to be very limited. Therefore, clinical translation of these products need appropriate animal models, stem cell manufacturing, and relevant regulatory processes. Certainly, it will increase the clinical use of stem cell-based cartilage in tissue engineering and regenerative medicine [113]. Induction is another important factor which is needed in tissue engineering and development of cellular healing types. Further, induced pluripotent stem cells iPSc are promising cell source for cartilage regeneration [114]. Hence, induction of chondrocytes from iPSc is made by using col2a1-EGFP factor. Further, for monitoring chondrogneic differentiation a fluorescent indicator has been developed which show great application in cartilage regenerative medicine. Similarly, a RoGel is developed for long self renewal of hpSCs [46].

Contrary to this, articular cartilage in living system show limited regenerative capacity. Because both types of cartilages, articular cartilage and permanent hyaline cartilage show significant differences in structure, extracellular matrix components, gene expression profile, and mechanical property from transient hyaline cartilage found in the epiphyseal growth plate. Moreover, in the process of synovial joint development, articular cartilage originates from the interzone, developing at the edge of the cartilaginous anlagen. This establishes zonal structure over time and supports smooth movement of the synovial joint throughout life. Further, cascade actions of key regulators, such as Wnts, GDF5, Erg, and PTHLH, coordinate sequential steps of articular cartilage formation. Hence, articular chondrocytes are restricted and controlled not to differentiate into a hypertrophic stage by using autocrine and paracrine factors and extracellular matrix microenvironment. But these retain potential to undergo hypertrophy [115]. Moreover, for increased knee cartilage volume in degenerative joint disease cutaneously implanted autologous mesenchymal stem cells are used [116].

\section{Bone regeneration}

Osteoarthritis $(\mathrm{OA})$ is a common disease involving joint damage, showing an inadequate healing response and progressive deterioration of the joint architecture. It occurs in aging joints, due to an injury or obesity (Figure 6). Its prominent disease symptoms are joint pain and stiffness in the affected joints after repetitive use. Pain persists throughout day and only slight relief occurs in non-moving state after a long rest. Joint pain increases with swelling, warmth, and creaking of the affected joints. Similarly, pain and stiffness of the joints also occur after pronged inactivity or non-moving for more than 3-4 hrs from a single place. But severe osteoarthritis displays complete loss of cartilage that increases friction between two adjoining bones which results in a severe pain at rest or pain with limited motion. Therefore, to remove friction and treatment of affected joints, including the hand, wrist, neck, back, knee, and hip, proper medication and physical exercise is required. Unlike many other forms of arthritis, such as rheumatoid 
Ravi Kant Upadhyay, Journal of Regenerative Medicine \& Tissue Engineering 2015,

arthritis and systemic lupus, osteoarthritis does not affect other organs of the body. However, for repairing injury autologous blood-derived products, such as platelet-rich plasma (PRP), are essentially required for tissue repairing and regeneration. These products can deliver a collection of bioactive molecules that have important roles in fundamental processes, including inflammation, angiogenesis, cell migration and metabolism in pathological conditions. More specifically, in osteoarthritis PRP platelet-rich plasma maintain anti-inflammatory properties and affect canonical nuclear factor $\mathrm{KB}$ signaling pathway in multiple cell types including synoviocytes, macrophages and chondrocytes [117]. PRP contains hundreds of different molecules; cells within the joint, if these are added to internal milieu by secreting additional biologically active molecules in response to PRP may provide greater relief. Therefore, PRP could be used to exploit its therapeutic potential, and for development of newer tissue-engineering methods and novel treatments for different stages of joint degeneration [117]. Furthermore, bone-regenerative potential of the periosteum and endosteum can also harnessed for tissue repairing by lineage tracing analyses. However, relative contributions of the periosteum in bone regeneration and its molecular and cellular mechanisms require involvement of BMP, FGF, Hedgehog, Notch, PDGF and Wnt factors that need further investigation [117] (Table 1). Therefore, to foster the novel approaches for bone-regenerative therapy inflammation signaling pathways in periosteal-mediated bone regeneration should be known. These approaches help dental surgeons to cure patients from serious bone injuries [117]. Similarly, estrogen receptor alpha in osteocytes play important for trabecular bone formation and show bone sparing effect that is mediated via estrogen receptor alpha and encoded by the Esr 1 gene [118].

\section{Regeneration of limbs and local tissues in invertebrates} Limb regeneration is a multi step process related to developmental biology, regenerative medicine and tissue engineering [119]. Though, this property lacks in higher animals but fetuses own this property and show growth of limbs in normal course. In amphibians limb growth occurs with the blood vessels that constrict to minimize the blood supply, injury site is covered by skin cells which transform in the epithelial cap, and send signals important for re-growth. It starts as soon as the resident fibroblasts leaving the surrounding extracellular matrix and migrates across the ampituation surface. Later on these migratory fibroblasts proliferate, differentiate and dedifferentiate to form aggregations of stem like cells called the blastema that assists in formation of new limbs. Other important factors, which contribute in this process, are innervations, cell spatial memory; chemical signals pass between cells, gene regulation, cell differentiation and inflammatory cells [120] (Figure 6).

Peripheral arterial occlusive disease (PAOD) contributes decreased exercise tolerance, poor balance, impaired proprioception, muscle atrophy and weakness. Its advance con- dition resulting in critical limb ischemia (CLI) in which viability of the limb is threatened. CLI patients show a poor life expectancy due to concomitant cardio and cerebrovascular diseases. Moreover, stem cell population of the lower limb plays important role in the management of CLI (Critical Limb Ischemia). Similarly, in Idiopathic small-fiber neuropathy (I-SFN), patients feel burning pain in distal extremities and autonomic dysfunction. It is a disorder of small-caliber nerve fibers of unknown etiology with limited treatment options. It arises due to effects of Nav1.8 mutation on activation and ramp current become dominant over the reduced persistent current. It also makes pro-excitatory gating changes that confer hyper excitability on peripheral sensory neurons, which may contribute to pain in this individual with I-SFN [121]. Mesenchymal stem cells (MSCs) are one of the main cell types that contribute to the recovery from ischemia because they generate several proangiogenic paracrine factors and differentiate MSCs into endothelial cells. MSCs showed different inductive capacities for recovering ischemic limbs [122]. However, therapeutic treatment for long bone fracture nonunion in limbs needs bone morphogenetic protein compounds which are combined with autologous red bone marrow graft [123]. Therefore, for successful union bone graft patients should avoid smoking during the treatment period. Other precautions are analysis of the original fracture, aggressive treatment of infection and all treatment related disorder must be investigated. Therefore, for developing better surgical solutions and applying fixation methods are used to reduce risk of failure of the graft [123]. In case of bone related diseases for example in case arthritis its level is evaluated from the degree of swelling at the peripheral joints of the fore and hind limbs muscle lesions. Muscle wasting might exacerbate joint swelling in a collagen-induced arthritis in animal models like cynomolgus monkeys $[124,125]$ (Table 1).

Lower invertebrates also show limb regeneration after having an injury. Some animals show lifelong ability of limb regeneration while others lose it during development. It can become an important area of research area in developmental biology; regenerative medicine and tissue engineering, if induction factors for regeneration in cells could be identified. Starting from protozoans, small ciliates such as Stentor, Blepharisma and Spirostomum are capable of cellular reconstruction. Similarly, sponges possess enormous power to regenerate. Sponge cells, which transform into adult animal, are archeocytes. If any sponge is rubbed on to a rough rock, it dislodges and few cells become free i.e., pinacocytes, chonaocytes and acheocytes that aggregate to form a new organism. Similarly, hydro polyp upon chopping forms a new individual from a cut off portion. In coelenterates interstitial cells are totipontent which proliferate and repair damaged tissues after moving towards these sites and form blastema. However, it is an important area of research to understand the differences between closely related regenerating and nonregenerating organisms, evolutionary loss of regeneration 
and its molecular mechanisms [126]. Notably, down regulation of canonical Wnt signaling in regeneration-deficient regions restores regenerative abilities while blastemas form new heads in regenerate tissues that normally never regenerate. Hence, manipulation of a single signaling pathway can reverse the evolutionary loss of regenerative potential [126] ( Table 1).

Among invertebrate planarians possess very high regenerative ability. These are used as important models for understanding the molecular basis of regeneration in higher animals. It is highly important that vertebrates lack this ability of regeneration. More exceptionally, few planarian species possess limited regenerative abilities, when they cut in lengthwise each part of the body will regenerate the missing half. Interestingly, regenerative blastema repairs the missing part, but few important reductions occur in size in regenerative and original animal it signifies epimorphosis. Similarly, nemertens show high regenerative ability and complete worm is formed from a very small segment. Platyhelminthes also possess high regenerating ability, but in nematodes this ability is low and they could only repair superficial wounds. Similarly, annelids both polychetes and oligochetes show regeneration of their anterior and posterior ends, but parasitic annelids do not show any regeneration. These animals also show epimorphosis, and a regenerating bud is formed which extend to form a new part. Moreover, regeneration in annelids is concerned to the growth stimulated by both local and systemic influences. Mollusks and arthropods show very low grade of regeneration, and renewal of lost part is very hard to repair. However, in crustaceans tissue damages are only repaired during development. While echinoderms mainly starfish, brittle stars and sea lilies show regeneration capacity and can repair arms and parts of discs. Brittle stars show very high tissue regeneration ability and repair lose limbs, but the rate at which this occurs is highly variable and species-specific. Though, a slowest rates of arm regeneration found in Antarctic Ophionotus victoriae. This property occurs due to presence of major gene families and pathways with potential relevance to the regenerative processes including the $\mathrm{Wnt} / \beta$-catenin pathway, Hox genes, the SOX gene family and the TGF beta signaling pathways [127].

In vertebrates regeneration, power is spectacular in the urodale amphibians mainly in newts and salamanders. These animals show regeneration of limbs and tail region, external gills and even the upper and lower jaws. But in adult anuran animals this property does not found. Other amphibians such as tetrapods mainly newts, axolotls, and frogs also show regeneration of lens and retina of the eye [128]. Reptiles mainly lizards show regeneration of tail region, and in their beak only. In mammals limbs do not regenerate spontaneously except fetal stages and regeneration only limits to wound healing of skeletal tissue and skin cells. Thus, invertebrates show capacity of regeneration much higher and it diminishes decreasingly in higher animals mainly in mammals. Mammals possess the remarkable ability and can regenerate a lost fingertip, including the nail, nerves and even bone. In humans, an amputated fingertip can sprout back in as little as two months but this phenomenon is poorly understood till date. But in other organs no regeneration occurs as it takes place in lower animals but in vertebrates this property only occurs in earlier stages of ontogenic cycle. For example, legs can be regenerated in tadpoles but this ability does not exist in adult frogs. Many fish and salamander species regenerate amputated fins or limbs, restoring the size and shape of the original appendage.

Regeneration requires spared cells to retain or recall information encoding pattern, a phenomenon termed positional memory. However, few factors play important role in positional memory during vertebrate appendage regeneration. More exceptionally, few potential regulators of anteroposterior (AP) pattern work together during fin regeneration in adult Zebrafish. There might involve many genes with regionspecific expression, several of them encode transcription factors with known AP-specific expression or function in developing embryonic pectoral appendages [129]. Transgenic reporter strains revealed that regulatory sequences of the transcription factor gene alx4a showed activated expression in fibroblasts and osteoblasts within anterior fin rays, whereas hand 2 regulatory sequences show activated expression same cell types within posterior rays [129]. More importantly, transgenic over expression of hand 2 in all pectoral fin rays did not affect formation of the proliferative regeneration blastema, yet modified the lengths and widths of regenerating bones. Hand2 also influenced the character of regenerated rays in part by elevation of the vitamin D-inactivating enzyme encoded by cyp24a1, it also contributes in region-specific regulation of bone metabolism [129]. Moreover, systemic administration of vitamin D during regeneration partially rescued bone defects resulting from hand 2 over expression. Thus, bone-forming cells in a regenerating appendage maintain expression throughout life of transcription factor genes that can influence AP pattern, and differ across the AP axis in their expression signatures of these and other genes [129]. Thus, extensive defects of the lower extremities are usually reconstructed with micro vascular free flaps because of inadequate local tissues and wound complexity. Though, efforts have been made to reconstruct such defects using the Chimeric flaps, which enable with larger surface areas to be used while maintaining economical tissue use [130]. The latissimus dorsi chimeric flap is one of the most useful tools for resurfacing extensive limb defects [130].

\section{Regeneration of skeletal myoblasts}

Skeletal myoblast or myocyte is striated muscle that contains transverse stripes and connected at either or both ends to a bone. It is a voluntary muscle made up of elongated, multinucleated, transversely striated muscle fibers having principally bony attachments. It is a muscle cell that helps in moving the parts of the skeleton. These long, tubular cells 
Ravi Kant Upadhyay, Journal of Regenerative Medicine \& Tissue Engineering 2015,

http://www.hoajonline.com/journals/pdf/2050-1218-4-1.pdf

doi: $10.7243 / 2050-1218-4-1$

develop from myoblasts and form muscles in a process known as myogenesis. These cells occur in various specialized forms of myocytes such as cardiac, skeletal, and smooth muscle cells, each of them show different properties. Cardiac myocytes or skeletal myoblasts are responsible for generating electrical impulses that control the heart rate (Figure 6). These cells are derived from skeletal muscle satellite cells upon an injury require cell-based cardiac repair $[131,132]$. Moreover, myoblasts derived from autologous or syngeneic sources show the ability to proliferate better than many cell types and trans-differentiate into cardiomyocytes. More specifically, myoblasts remain stubbornly committed to form mature skeletal muscle in the heart [133-135] with the exception of rare cell fusion events at the graft-host interface [136]. Skeletal muscle is one of the few cell types in the body that does not normally express gap junction proteins and do not form electromechanical junctions with cardiomyocytes when engrafted into the heart [137].

Similarly, cardiomyocytes are optimal cell type to repair an infarct. These stem cells provide an alternative curative intervention for the infracted heart by compensating for the cardiomyocyte loss subsequent to myocardial injury. Other committed cell types such as fibroblasts and smooth muscle cells, which clearly cannot contract like cardiomyocytes, but enhance function of the injured heart (Figure 6b) [138]. However, cell based repair mechanisms include increasing perfusion through angiogenesis and arteriogenesis improves the infarct connective tissue and generates less ventricular dilation and enhance the myocyte survival. However, presence of resident stem and progenitor cell populations in the heart, and nuclear reprogramming of somatic cells with genetic induction of pluripotency markers are emerging developments in stem cell-based regenerative medicine. Further, fetal cardiomyocytes could form stable grafts in uninjured hearts of syngeneic recipients [139]. However, safety and feasibility of these cells is established by extensive experimentation in vitro and in vivo experimental models. No doubt, skeletal musclederived myoblasts, and bone marrow cells remain the most well-studied donor cell types for myocardial regeneration and repair. Similarly, transplantation of myoblast-based therapeutic intervention may augment myocardial function in the infracted heart. Therefore, new strategies which can overcome the problem of arrhythmogenicity and failure of the transplanted skeletal myoblasts are much needed (Figure 6) [140].

Bone marrow derived mesenchymal stem cells (BMdMSCs) can differentiate into cardiomyocyte-like cells induced by different inductors individually or collectively. However, by inducing BMdMSCs with $\mathrm{p} 53$ inhibitor ( $p$-fifty three inhibitoralpha, PFT-a), 5-azacytidine (5-AZA), angiotensin-II (Ang-II) and bone morphogenic protein-2 (BMP-2) influences four inductors of differentiation of rat BMdMSCs into caridomyocyte likecells [141] (Figure 6b). Further, for differentiation of BMdMSCs into cardiomyocyte-like cells combination of inductors and expressions of cTnT, cTnl and Cx43 are essentially needed to develop new cardiac regenerative medicine. In addition, constitutively activating mutation (R206H) of the BMP type I receptor, activin-like-kinase 2 (ALK2), causes fibrodysplasia ossificans progressive (FOP). It is characterized by extensive ossifications within muscle tissues. However, Tmem 176b mRNA levels were found up-regulated by stable transfection of ALK2 (R206H) in mouse myoblastic C2C12 cells (Table 1). Similarly, transient Tmem 176b overexpression also elevate levels of osteoblast differentiation markers, such as Osterix and alkaline phosphatase, as well as mineralization in $\mathrm{C} 2 \mathrm{C} 12$ cells. In addition, Tmem $176 \mathrm{~b}$ over expression elevate the levels of these markers in mouse osteoblastic MC3T3-E1 cells and induces the differentiation of myoblasts into an osteoblast lineage [142]. Cardiomyocyte-like cells are produced from secondary CSs under ERK inhibitory conditions [143] while cardiac differentiation of BMdMSCs is induced by PFT-a, 5-AZA, Ang-II and BMP-2. But PFT-a has an advantage of differentiation rate and electrophysiological function over other inductors (Figure 6). Thus massive interactions occur between muscle tissues and bone metabolism during regeneration.

\section{Regeneration of diverse cardiac, smooth muscle and endothelial cell lineages}

Heart diseases consist of progressive condition involving loss or defects of cardiomyocytes. Despite so many treatment regimens, heart failure remains one of the leading causes of morbidity and mortality worldwide. This is due to failures and lack of adequately replacement of lost ventricular myocardium from ischemia-induced infarct. Because adult mammalian ventricular cardiomyocytes show limited capacity to divide, and its proliferation is insufficient to overcome the significant loss of myocardium from ventricular injury. Heart muscles show low endogenous regenerative capacity (Figure 6b), hence, there is a need of novel regenerative medicine approaches because existing therapeutic approaches could not low down the cases of heart failures. Therefore, new therapies that could assist in regeneration of damaged cardiomyocytes or myocardium cells are essentially needed to improve or restore structure and function of human heart. As the search for new cell types for cardiovascular regeneration continues, it is equally important to optimize ex vivo cell processing and to develop optimal processing strategy for human cardiac progenitor cells. Therefore, for generation of functional cardiac muscles or cardiomyocytes in situ for cell transplantation-based therapies direct reprogramming of endogenous cardiac fibroblastsis is essentially needed. Interestingly, functional cardiomyocytes can also directly generate from fibroblasts by using several combinations of cardiac-enriched factors or could also achieve by in vivo gene delivery of cardiac reprogramming factors [144]. Moreover, efforts are continued for generating de novo cardiomyocyte-like cells from terminally differentiated nonmyocytes in the heart in situ after ischemic damage (Figure 6). For which, all essential transcriptional molecules and more 
advanced cardiac reprogramming methods and high-grade technology are essentially required [145]. By using successful cell programming new cardiac muscles can be generated and implanted to improve heart functions after myocardial infarction in man. No doubt, generation of cardiac muscles from stem cells will prove highly useful alternative strategy to regenerate the cardiac muscles. This will not only repair failures of adult cardiomyocytes in adults, but also cure congenital heart diseases and restore cardiovascular disorders (Figure 6).

Furthermore, use of cardiac stem cells (CSCs) and tissueengineering methods will be more promising for restoration of cardiac muscle cell failures. Further, heart regeneration studies in animal models will provide alternative ways to find and set new therapeutic targets and opportunities. For example, amnion is used as an ideal cell source for cardiac muscle regeneration for therapy. More often, regenerative therapeutics could be achieved by using differentiation potency of the human amnion mesenchymal cells (hAMCs). It could also improve by over expression of Oct4, a key factor that maintains the undifferentiated state [146]. These hAMCs activate to an undifferentiated state by over expression of Oct4, and their cardiac differentiation potency can be improved. Thus, the single-time transfection of the Oct4 expression vector may be a useful strategy for effective cell therapy. No doubt regenerative therapy is considered more promising strategy for the end-stage heart failures.

However, by enhancing the stemness potential and promoting the secretory activity for paracrine glands cellular potency and humoral activity can be increased [146]. Therefore, identification of precise paracrine signals that drive the cellfate decision of multipotent progenitors is an important aspect for development of novel approaches to deliver these signals in vivo, and unlocking their regenerative therapeutic potential. These signals have been identified in form of family of human cardiac endothelial intermediates located in outflow tract of the early human fetal hearts (OFT-ECs). It is characterized by co expression of Is 11 and CD144/vWF factors [147]. Furthermore, vascular endothelial growth factor (VEGF)-A was identified as the most abundantly expressed factor, that also showed the ability to drive endothelial specification of human embryonic stem cell (ESC)-derived $|\mathrm{s}| 1^{+}$progenitors in a VEGF receptor-dependent manner [147]. However, over expression of VEGF-A promotes not only the endothelial specification but also engraftment, proliferation and survival (reduced apoptosis) of the human Is|1+ progenitors in vivo. Thus, large-scale derivation of cardiac-specific human Is|1-ECs from human pluripotent stem cells, coupled with the ability to drive endothelial specification, engraftment, and its survival following transplantation [147]. Such novel experiments on vascular regeneration might possible in heart of mouse and Zebra fish regenerative models which possess crucial genetic and epigenetic factors that stimulate vascular regeneration in the heart [148].

A major problem of injured heart is animal-to-animal variability in wound size. Therefore, cryo-models are used because they provide an extended injury border zone that exhibits classic markers of remodeling found in surviving cardiac tissue at the edge of a myocardial infarction, including connexin 43 (Cx43) lateralization. However, to deliver a cryo injury to the apex of the heart of neonatal mice may be more useful for studying myocardial regeneration in mammals [149]. Interestingly, lower vertebrates, such as the Zebra fish and newt, have the remarkable capacity to fully regenerate their hearts after severe injury. Thus, experiments with animal model systems may be more useful to discover new regenerative approaches that might be applied to injured mammalian hearts. Among various animal model systems Zebra fish is used because of its genetic tractability which also provides additional mechanistic insight into cardiac regeneration [150].

Distinct families of multipotent heart progenitors play a central role in the generation of diverse cardiac, smooth muscle and endothelial cell lineages during mammalian cardiogenesis (Figure 6). Few important structures like human right ventricular tissues and primary cardiosphere (CS), primary CS-derived cells (PCDC) and secondary cardiospheres (SCSs) can also regenerated by reprogramming. More specifically, during formation of secondary CS, the ERK pathway is inhibited by using selective RTK 1 and TGF- $\beta$ inhibitors. But Oct 4 get increased 20 fold and VEGF decreased. Moreover, when the ERK pathway is stimulated by addition of EGF and TGF- $\beta$, VEGF expression get up-regulated and Oct 4 down regulate (Table 1). No doubt ERK pathway plays a directional role for maintaining cellular potency versus paracrine capacity [143]. More often, transplantation of PCDCs or secondary CSs into the infracted heart of immune-compromised mouse showed significant angiogenic effects and generate cardiomyocyte-like cells from secondary CSs under ERK inhibitory conditions [143]. It makes clear that combined transplantation of specifically-processed human secondary CSs enhance infarct repair through the complementary enhancement of cardiopoietic regenerative and paracrine protective effect that can be maximize for achieving higher therapeutic benefits [143].

Cardiac development is a complex process resulting in an integrated, multi-lineage tissue with developmental corruption in early embryogenesis leading to congenital heart disease. Further, establishment of specific characteristics of each embryonic cardiac chamber is very crucial for development of a fully functional adult heart. It is well known that chamber deformities emerge gradually during development, with a severe collapse in the number of ventricular cardiomyocytes and an accumulation of excess atrial cardiomyocytes as the heart matures [151]. For this purpose, maintenance of unique features is required both in ventricular and atrial cardiomyocytes [151] by using regulatory mechanisms mainly using homeodomain transcription factors $\mathrm{Nkx2.5}$ and $\mathrm{Nkx2.7}$. These are necessary to sustain ventricular chamber attributes through repression of atrial chamber identity. However, for maintaining ventricular identity and remarkable plasticity 
in differentiated myocardium Nkx genes play a pivotal role. Hence, mutations if occur in nkx2.5 gene in Zebra fish it may yield embryos with diminutive ventricular and bulbous atrial chambers [151]. Further, removal of $n k x 2.7$ function from nkx2.5 mutants exacerbates the loss of ventricular cells and the gain of atrial cell. This is the main reason that $n k x 2.7$ deficient embryos ventricular cardiomyocytes cannot transform into atrial cardiomyocytes. Thus, improvement of $n k \times 2.7$ gene function may be more usable in fetal and neonatal cardiac pathology and cardiac regenerative medicine [151] (Table 1).

Meanwhile, interrogation of individual genes play important role in cardiac development which requires a comprehensive transcriptome derived from natural cardiogenesis to gauge innate developmental milestones. More specifically, differential gene expression within the pluripotent state revealed 23 distinguishing candidate genes employed among pluripotent cell lines with divergent cardiogenic potentials. Moreover, a confirmed panel of 12 genes is required for differentially expressed cardiomyocytes between high and low cardiogenic lines. More specifically, a panel of development-related genes allowed differential prognosis of cardiogenic competency, and prioritizing cell lines according to natural blueprint to streamline functional applications [152]. This panel of genes transforms cells into to discriminate individual iPSC lines according to relative cardiogenic potential. Moreover, transcriptome analysis attuned to natural embryonic cardiogenesis provides a robust platform to probe coordinated cardiac specification and maturation from bioengineered stem cell-based model systems. Interestingly, matrix metalloproteinase-9 (MMP9) induces fibrosis that causes stiffness of the ECM and impairs differentiation of cardiac stem cells into cardiomyocytes [65]. It clears that stem cells possess enough therapeutic potential to cure cardiac diseases [153].

\section{Repairing of adipose tissue damage}

There are many promising treatment approaches which have shown enormous potential in regenerative medicine for tissue engineering and somatic nuclear transfer (SNT) (Figure 7) [154]. However, mammalian adipose tissue derived stem cells are used for repairing tissue defects. For this purpose, preadipocytes are delivered to sites where adipose tissue damage needs to be repaired. Hence, injectable hyaluronic acid/adipic acid dihydrazide (HA/ADH) hydrogel an adiposetissue-like material was prepared that showed biological compatibility as well as stiff mechanical behavior upon use. This also supports growth, proliferation and differentiation of 3T3-L1 pre-adipocytes and serves as a vessel for protecting pre-adipocytes for short-term after delivery to native tissues [155]. Adipose tissue is a weight-bearing biological structure that needs many biological molecules for explant growth. Moreover, adipose derived stem cells are used to improve

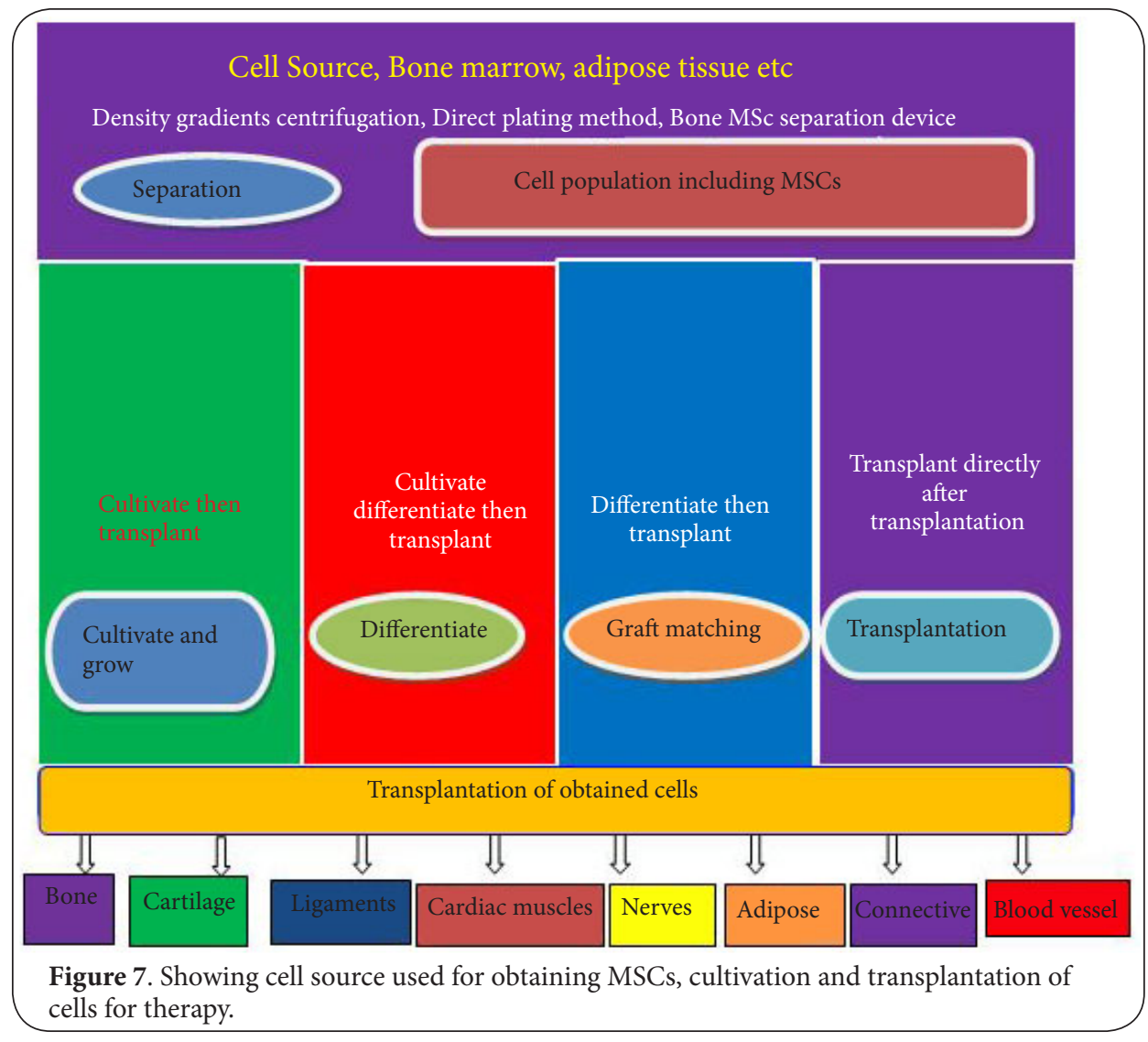


cartilage defects and injuries. These cells show increased proliferative and chondrogenic capabilities like platelet rich plasma treated adipose stem cells. Adipose stem cells are used for clinically acceptable therapies mainly for cartilage regeneration [156]. ASCs derived from adipose explants can differentiate along multiple lineages in vitro [157]. Though, adipogenic differentiation of adipose-derived stem cells (ASCs) affected by many promoting and inhibiting factors [157] (Figure 7). It is widely concerned with surrounding cells and extracellular matrix. However, by utilizing SFAE, the proliferation and colony-forming efficiency of ASCs is inhibited, while the expression of adipogenesis markers such as $C / E B P \beta$, PPAR 2 , and $L P L$, as well as angiogenesis factor VEGF-A are promoted. No doubt SFAE put beneficial influence on adipogenesis and angiogenesis both in vitro and in vivo [157]. Therefore, for harvesting adipose-derived stromal cells (ASCs) suction-assisted lipoaspirate liposuction is used for tissue engineering to avoid negative effect on ASCs [74].

\section{Regenerative gonadial tissue damage repairing}

Embryonic stem cells or induced pluripotent stem cells are used to produce oocytes but these cells show very limited success in vitro oocyte production. For this purpose, endogenous oocyte producing or oogonial stem cells (OSCs) are obtained from ovaries of adult reproductive females and seeded for maintenance of human female germ cell cultures. Thus, stable and pure human female germ cell cultures are maintained by using certain growth factors and transcription factors. But growing germ cells must show completion of meiosis in vitro (Figure 8) [158] (Table 1). OSCs are also used for transplantation into adult human ovarian cortical tissue for generation of functional oocytes that arrest at the diplotene stage of meiosis. Thus, successful recruitment of granulosa cells allows formation of new primordial follicles. However, well nourished cell culture systems are used for in vitro gametogenesis from stem cells mainly generation of human oocytes. These are used to solve the problem of sterility in reproduction deficient human females [158]. Similarly, functional male gametes i.e., spermatocytes or spermatids can be generated in artificial medium from reproductive human males by culturing Leydig cells in artificial medium. But hALR content, TSPY (Testis specific protein, $Y$ encoded) promoter are essentially required for induction of spermatogenesis in males [159], because expression of hALR influences sperm morphology, quality and eventual reproduction in male fertility [159]. Similarly, progenitors of $Y$ gene specific stem cells mainly progenitor Leydig cells may play important role in removing male sterility if such cells could maintain in artificial medium.

Similar regeneration of Sertoli and interstitial cells may also support the germinative cells in production of gametes. In addition, Sertoli cells can be trans-differentiated in to male gamete forming cells (MGFCs). Similarly, implantation of progenitors of primordial germ cells in males may help in formation of male gametes. Further, abdominal coelomic epithelium regeneration may help in repairing scrotal sac and other male gonad injuries. More often, organelle specific gene transplantation in sperm cells may help in formation of fully active functional acrosome, axial filament and mitochondrial proteins to make the male gametes vital and active. Thus, for making actively moving sperms, tail portion can be regenerated by incorporating motility inducing protein implants or more wisely transfer of its genes.Interestingly in new cells mitochondrial function, energy healing and genomic stability can be evoked and afresh by channelizing gene functions and biological signals from sperm nucleus. NGF might also play important role during Leydig cells (LC) regeneration by regulating the proliferation and differentiation of these cells at different developmental stages, from SLCs, to PLCs and from PLCs to ILCs [160]. NGF significantly promotes the proliferation of stem /Leydig cells and also induces steroidegenic enzyme gene expression and 3beta -HSD protein expression [160. DEHP increases Leydig cell proliferation but inhibits differentiation during the regeneration of Leydig cells [157]. Thus by using cell and gene based therapies functional maturation, time differences in males and female sexes can be corrected. Stem cell-based strategies are used for ovarian regeneration and oocyte production in infertile women.

Similarly, healing and repairing of ovarian follicles is also possible by making transplantation of ovarian stem cells in infertile females (Figure 8). It can be preceded by using progenitor cells from ovarian epithelium. It is a single layer of poorly differentiated epithelial cells that covers the surface of the ovary and ruptures during ovulation. These cells exhibit progenitor/ stem cell characteristics and express the stem cell marker lymphocyte to antigen 6 complex, LY6A which is also known as stem cell antigen-1(SCA-1). These cells LY6A and mouse ovarian surface epithelium progenitors may play a role in ovulatory wound healing [161]. However, in vitro grown follicle cells can be implanted in sexually defective women. These follicular cells transform into columnar epithelium and form membranous bound area the zona pellucida between the oocyte and primary follicular epithelium. Thus, cell programming factors are naturally being made available for follicle cell formation that helps in repairing and improvement of all-germinal defects in ovarian tissues. No doubt it will support sexual maturation in sexually deficient females. Though, success rate of cellular activation and adaptation in new environment may be below $5 \%$ but it will open new innovative area in the field of reproductive biology. Further, regeneration of degenerating follicles is also possible but restoration of cell functions needs normal supply of progesterone from corpus luteum. Moreover, progenitors of follicles, luteal cells and stromal cells can help in formation of oocytes, repairing of uterine endometrium and oocyte implantation. However, muscular layer and mucous membrane should be implanted in uterine endometrium to treat and remove the ovarian cancer.

More specifically, homologs of nanos are required for the formation and maintenance of germ line stem cell (GSC) systems. 


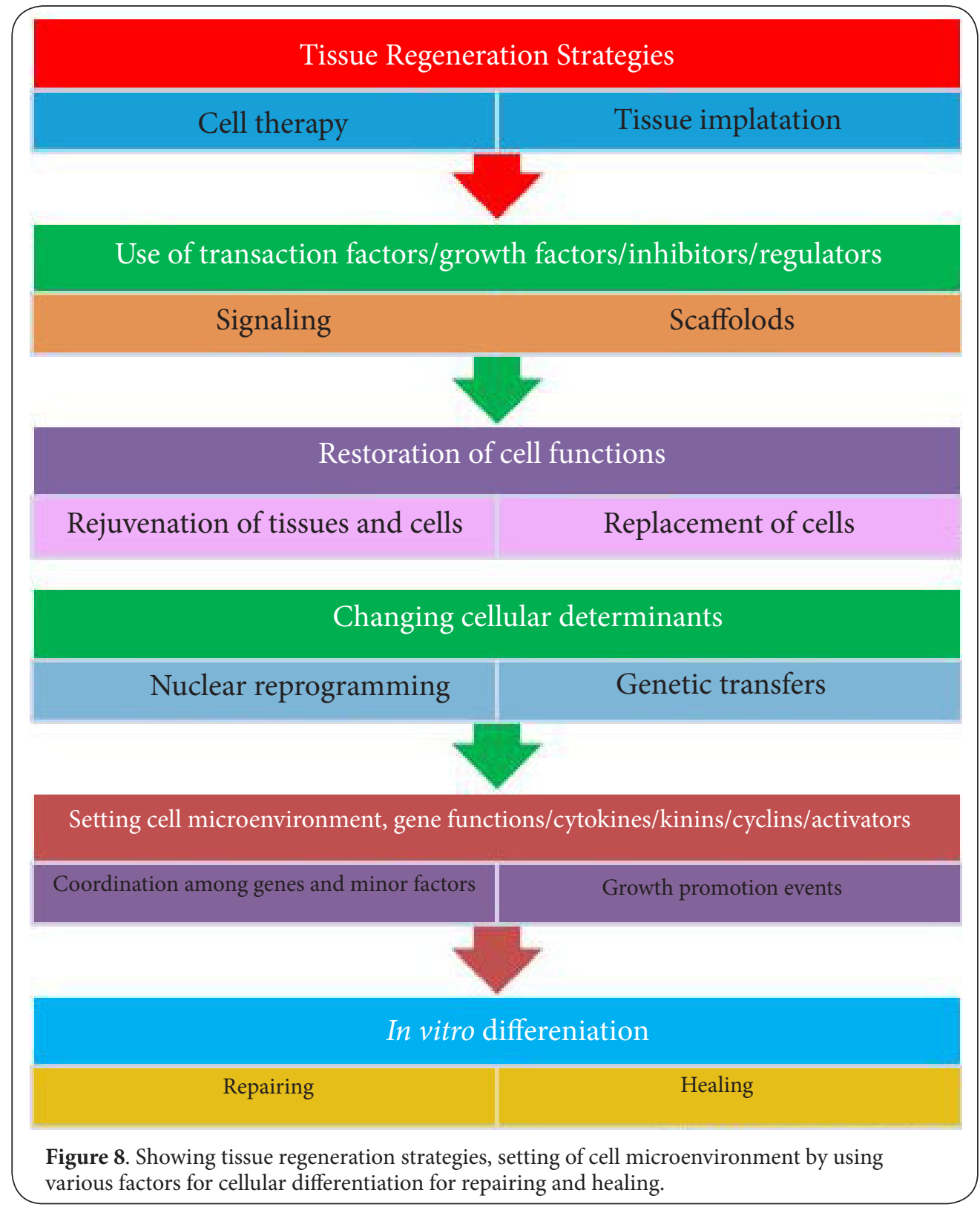

These are essentially required for gametogenesis in many metazoans. For example, planarians change their reproductive mode seasonally, alternating between asexual and sexual reproduction. These animals develop and maintain their somatic stem cells (SSCs) and GCSs from pluripotent stem cells known as neoblasts. Similarly, Dr-nanos was found essential for the development of germ cells in the ovaries and testes at an early stage of germ cell specification, but these do not participate in the development of somatic sexual organs (Figure 7) [162].

Moreover, other methods that could assist in cell and gene therapies are nuclear transplantations and animal cloning. But these studies are illegal and unethical and against natural laws in case of man. Interestingly, animal clones were prepared by nuclear transplantation of cleavage stage nuclei in ovine eggs $[163,164]$. However, for nuclear transplantation unfertilized recipient eggs are used and not the fertilized zygote. But Campbell, Wilmut and colleagues [165] used Willadsen technique and procure nuclei from adults to produce live off springs. It was also followed for generation of famous cloned sheep Dolly $[166,167]$. Similar nuclei transplantation experiments were conducted by using advanced endodermal cell nuclei from tadpoles Xenopous laevus. In addition, transspecies transplantations are also possible that may help to decide role of sex specific genes in generation of ovarian and testicular follicles, if they are incorporated or induced in artificially generated somatic or mitotic cells tissues. In addition, cross roads of sex specific programming could be 
determined but it seems impossible in near future.

Furthermore, more appropriate organ transplants can be generated by transplantation of human genes insides stem cell progenitors or by reprogramming cellular functions. But for this purpose different transcription and growth factors are to be required having specific cell types. Moreover use of these factors can improve the cases of graft rejection because both tissue and cell transplantations follow proper cell lineage and growth regulatory mechanisms (Figure 8). But it seems to a toughest job because two different cell lineages essentially need different microenvironments during development and differentiation stages, because in adult organism stem cell reside in defined anatomical environment or niches. Hence, architecturally diverse microenvironments should be maintained to serve to balance stem cell self-renewal and differentiation [168]. Similar, germ line stem cells are also found in adult flies and worms which maintain their own micro-environment or niche themselves. It is much similar to ecological niche where every biological entity maintains its life. Microenvironment supports the cell division in stem cells and other biological activities. Thus, it is clear that cell feels effect of both intrinsic and extrinsic factors mainly regulatory proteins, which help to sustain stem cell population (Figure 7).

In Drosophila in the ovary niche is maintained by secretion of two types of proteins namely transforming growth factor $\beta$ (TGF $\beta$ ), protein (Dpp and Gbb) and Hedgehog CHh) protein. Factors Hh, Dpp, and Gbb cap maintain cell derived signals in coordination to cell surface proteins (Figure 8). Similarly, both Arm and Zpg direct a cell to remain stem cell. Similarly, microRNAs control the cell division properties of Drosophila female germ line stem cells. Similarly, cyclin E-CDK complexes, Wnt signal and $\mathrm{Hh}$ protein also play important role in maintainace of micro-environment. While Drosophila BCL6 homolog Ken and Barbie promote somatic stem cell self-renewal in the testis niche [169] (Table 1). Notch pathway remains active during embryogenesis prior to the development of hematopoietic system, but hematopoietic differentiation is inhibited when notch activity is enhanced [121]. Similarly, Notch signaling pathway promotes mitotic union of worm germ line stem cells. A membrane protein Delta binds to the Notch receptor on the germ line stem cell and establishes stiffness of extracellular matrix (ECM) and surrounding niche/microenvironment that play pivotal roles in ESC differentiation [65]. A proper microenvironment is required for ES cells to differentiate to form multicellular aggregates or embryoid bodies much similar to the early embryos. Similarly, a proper regulation of balance is required for tissue repair and homeostasis. Any imbalance can potentially lead to diseases such as cancer [168]. However, a proper microenvironment is required for ES cells to differentiate to form multicellular aggregates or embryoid bodies much similar to the early embryos. Thus, activated embryonic stem cells can differentiate in to various cell types with the help of transcription factors, Nanog, Soc2 and Oct 4. However, for achieving therapeutic excellence in the field of clinical medicine high through put technologies and combinatorial methods are essentially required for stepwise engineering of stem cell microenvironments for stem cell based therapies (Figure 8) [168].

Adult stem cells support tissue homeostasis and repair throughout the life of an individual. But during ageing, numerous intrinsic and extrinsic changes occur that result in altered stem-cell behavior and reduced tissue maintenance and regeneration. In the Drosophila testis, ageing results in a marked decrease in the self-renewal factor Unpaired (Upd), leading to a concomitant loss of germ line stem [170]. More specifically, a IGF-II messenger RNA binding protein (Imp) counteracts endogenous small interfering RNAs to stabilize Upd (also known as os) RNA. Similar to upd, Imp expression decreases in the hub cells of older males, which is due to the targeting of Imp by the heterochronic microRNA let-7. In the absence of Imp, Upd, mRNA remains unprotected and become susceptible to degradation (Table 1). Thus, for understanding mechanistic basis for ageing-related changes in stem-cell behavior newer strategies are required to treat age-onset diseases and facilitate therapeutic importance of stem-cell-based therapies in older individuals [170]. Stem cells sustain tissue regeneration by their remarkable ability to replenish the stem cell pool and to generate differentiating progeny Issigonis [169].

Similarly, in Drosophila testis, a group of somatic support cells called the hub creates a stem cell niche by locally activating the Janus Kinase-Signal Transducer and Activator of Transcription (JAK-STAT) pathway in two adjacent types of stem cells: germ line stem cells (GSCs) and somatic cyst stem cells (CySCs) [171]. In addition, both ken and barbie (ken) are autonomously required for the self-renewal of CySCs but not GSCs. Ken represses a subset of Stat92E targets in the embryo [172]. It also maintains CySCs by repressing differentiation factors. Furthermore, Ken mis expression in the CySCs lineage induces the cell-autonomous self-renewal of somatic cells as well as the non-autonomous self-renewal of germ cells outside the niche. Thus, Ken, like Stat92E and its targets ZFH1[170] and Chinmo [173] are necessary for CySCs renewal [69] (Table 1). Contrary to this, ken is not a JAK-STAT target in the testis, but instead acts in parallel to Stat92E to ensure CySCs self-renewal. Thus global JAK-STAT inhibitor Protein tyrosine phosphatase 61F (Ptp61F) is a JAK-STAT target in the testis that is repressed by Ken. It also plays an important role in the inhibition of CySCs differentiation [169]. The let-7-Imp axis regulates ageing of the Drosophila testis stem-cell niche [170]. More often, micro niche affect oocyte formation by mitotically active germ cells obtained from ovaries of reproductive-age women [174].

\section{Regeneration of immune power}

It is very difficult to induce regeneration in immune cells because of lineage difference and coordination of immune response signals and behavior of immune surveillance cells [175]. But few cells like hematopoietic, dendrocytes, Kupffer 
Ravi Kant Upadhyay, Journal of Regenerative Medicine \& Tissue Engineering 2015,

cells derived from embryonic stem cells and laboratoryderived cell lines of pre-implantation blastocyst-origin may, retain some immunological properties. It is true that, immune privilege provides protection to vital tissues or cells of the body when foreign antigens are introduced into these sites [176]. Moreover, variety of tissues and anatomical structures, including the hair follicles and mucosal surfaces, and sites of chronic inflammation and developing tumors may acquire immune privilege by recruiting immunoregulatory effector cells, but adult stem cells are no exception. Thus for regenerating immune vitality in cells both pre and progenitors of different factors and molecules are required for generation of different cells types and lineages. Hence, all necessary genetic and molecular factors are essentially required that is fulfilled by stem cell microenvironment. It proceeds and establishes immune cell reprogramming, and evokes difference between self and non-self substances. However, it is true that immune privilege can be developed to extend the capacity of adult and embryonic stem cells to display both relative and acquired immune function and to harness large therapeutic gain [176]. More specifically, embryonic stem cells and their differentiated tissue derivatives transplanted into a recipient do not necessarily have an ability to subvert immune responses to the extent required to exploit their pluripotency for regenerative medicine [176]. Therefore, a pre-implantation-stage embryo that derives from a totipotent stem cell (i.e., a fertilized oocyte) must be protected from maternal allo-rejection for successful implantation and development to occur, because so many factor work in simultaneous or in synchronizing way during regeneration and wound healing of tissues and organs. More often, immune perfection in implanted cells, tissues, parts may need restoration of structural genes and transplantation and growth factors. However, regeneration of immune cells may start immune responses in immune deficient individuals, which will open new gateway of autoimmune disorders and virus generated deficiencies such as loss of CD cells and its receptors, signal recognition molecules and adhesion molecules. Thus, capability of immune function can be enhanced in both ways by inducing immune cell system and by generating important immune molecules in vitro to restore the biological functions of the patient's body. Furthermore, restoration of cellular and molecular configuration of antigens may lead to the revolution in the field of biomedicine.

Further, transplantation of mast cells, resident of several types of tissues contains many granules rich in histamine and heparin. These cells show very important role in wound healing and defense against pathogen. These cells not only restore the functions of blood vessels, but also do structural restoration of skin cells, mucosa of lungs and digestive tract, conjunctiva and nose. Thus, abnormalities of immune cells to which the patients are susceptible to a variety of infections, phagocytic and macrophages abnormalities can be improved. Further, MHC genes and its gene products can help in transplantation and avoid risks of graft rejection. Primarily some of the cells, which induce immune responses, may be restored by programming the action of cytokines, interleukins and complementary system. However, follicular dendritic cells, which do not display MHC II, can be restored. Contrary to this, precursors of mast cells, which are formed in the bone marrow, are released in to the blood as undifferentiated cells which maintain phagocytic function. These cells contain large cytoplasmic granules having antibacterial substances like histamine and may show different types of allergies. These cells occur in wide variety of tissues i.e., skin, connective tissues of various organs, mucosal epithelium of respiratory and digestive system and genitourinary tract. Similarly, dendritic cells also occur in different organs and recognized as Langerhans DCs, interstitial, DCs, monocyte derived DCs, and plasmatocytoid derived DCs. However, DCs present in skin cells are repairable. Plasmatoid derived DCs which play important role in innate immune defense and work like antigen presenting cells. If cell culture derived DCs are released in the blood immune compromising patient, up to some extent their immune functions can be restored. Thus, interactions between CD4+ T lymphocytes and antigen presenting cells can be improved. For example in vitro culture of dibetogenic CD4+ and CD8+ T cells with NOD, RAG1and culture of Islets in vitro transwell system led to secretion of candidate cytokines/chemokines such IL-2, IL-6,IL-10, MIP-1a and RANTES. Thus, cellular factors/ soluble factors secreted from T cells together enhance $\beta$ cell proliferation and prove potential therapeutic candidates in controlling type 1 diabetes [177] (Figure 8) (Table 1). Hence, restoration of immune signals may help in intercellular recognition of self and non-self in organ transplantation and autoimmunity. Further, it may also help to identify cellular interactions, co-stimulated and accessory, But there are lesser possibility in healing of innate immunity, mainly restoration of pathogen associated molecular patterns (PAMPs) and other receptors of innate immunity which are encoded by host germ line.

\section{Future clinical prospects}

Regenerative medicine has wider application in the field of tissue repairing, wound healing and transplantation therapeutics. Moreover, by making more vital cell and tissue transplantations repairing of cerebrum injuries due to accidents, septal or acute syndrome shocks, mental and conscious activities of brain and integrative function can be restored. But, restoration of memory and intelligence are very difficult tasks to achieve because regeneration of neurons in all cerebral/CNS diseases is impossible. Though new innovations in regenerative medicine gave hopes for repairing of thalamus nuclei or small clusters of nerve cells, hypothalamic neurons, nephrons in kidney and Malpighian Corpuscles. More often, this could be achieved by cellular reprogramming at an earlier stage of disease. Similarly, repairing of flattened cells or podocytes of Bowman's capsule may help to restore blood supply in renal artery in kidney, glomerular capillaries, 
afferent arterioles, and peritubular network of capillaries. More espcifically, sqmuamus epithelium could also restore by regeneration of endothelium, and basement membrane of the wall of glomerulus capillaries. Thus, functional restoration of secretion of $\mathrm{ADH}$ and aldosterone and ultra filtration could maintain osmoregulation in blood circulation in micro capillaries or nephrons in kidney tissues.

However, for development of more advanced therapies fine candidate molecules responsible for cell programming must be identified. These are also used for generation of real time micro niche to obtain highly specific cell types that could repair structural deformities caused by viruses and other pathogens at cellular level. But it seems to be a challenging task and costliest un-imaginable affair to restore ATPase receptors and other energy or electron accepting ports located on the membrane surface. Similarly, improvement of transmitting signals for touch, smell, vision and hearing is a very difficult to restore, but sensory cell implantations could be possible by converging stem cells into somatic sensory cells. In addition, reprogramming for repairing the loss of vision in retinal cells, restoration of ultra filtration and ionic potentials in neurons, and hormonal secretion in pancreatic cells could be achieved by cell replacement therapies. Interestingly and spinal cord injuries and memory functions of sensory cells can be restored through reprogramming. Similarly, soluble factors secreted from $T$ cells are also identified as potential therapeutic candidate to enhance beta cell proliferation for onset of type 1 diabetes [177]. No doubt gene transfer can restore secretion of certain factors like BMP, FGF, Hedgehog, Notch, PDGF, Wnt and inflammation signaling that may assist in bone regeneration [178]. Further, markers for regeneration of cartilage bone, cardiac muscles, adipose tissue, neurons, skin, and hematopoietic, liver and ovarian cells can create reforms in clinical medicine and research. Though it is also impossible to find solution of brain injuries mainly (neuronal) occurred due to effect of nerve poisons, virus toxins, electronic shock and radiation certainly it will become a most innovative research area for the future.

Though, few successes have been obtained related to repairing of tendons, cartilages, skeletal muscles, liver tissues and in bone regeneration. But new promising biomaterials and methods are highly demanded for therapeutic purposes to restore organ level deformities [179]. Meanwhile stem cells (MSCs) are implanted or injected into damaged tissue while stem cell progenitors are used to replace defective cells. However, for development of novel treatments, newer tissue repairing strategies and both biological and synthetic solutions are being made available for providing advanced clinical aids to the patients. In addition, inherently suitable scaffolds and matrices are to be generated for tissue engineering, stem cell propagation and differentiation. Now it become possible to use bio-engineered organs and tissues, though its replacement is very difficult to proceed and practiced for disables [180]. Contrary to this, meniscus regeneration remain unsolved and a clinical challenge despite the wide acceptance of the degenerative consequences of meniscectomy and no surgical procedure has succeeded to date in regenerating a functional and long-lasting meniscal fibrocartilage. More often, none of the existing approaches has been completely successful for all patients, as meniscal tears require specific and patient-related treatments depending on the size and type of lesion [181]. Therefore, there is an utmost requirement of new methods or strategies for having new potential regenerative medicine based on cell-free scaffolds, gene therapy, intra-articular delivery of progenitor cells, biological glues for joining broken bones, disarticulated tendons, muscle fibers, reparable tears, partial and total tissue engineered meniscus replacement [182].

Further, regenerative medicines may also have important role in reprogramming of cells to check the ageing or maintain reversal of ageing process. But, it is a greatest challenge because during ageing, numerous intrinsic and extrinsic changes followed which influence stem-cell behavior and reduce tissue maintenance and regeneration. Hence, mechanistic ageing-related changes in stem-cell behavior cannot be restored. But there is a possibility for development of strategies to treat age-onset diseases and facilitate stemcell-based therapies in older individuals [170]. Hence, there was felt a strong need of new reagents that could activate recruiting of intrinsic and extrinsic factors to induce implant progenitor cells into the damaged sites for repairing of tissues in old age people [115]. Similarly, it is also an important area of research to identify and use totipotency factors in the ooplasm and epigenic reprogramming of the transplanted genes. Does somatic epigenomic can be reprogrammed to achieve pluripotent state by combination of transcription factors [181]. How long individually tailored stem cells can be used for therapeutic purposes will be new innovative areas of future research [183]. Thus by recruitment of intrinsic stem / progenitor cells in to the damaged sites can start regenerative activity and can make disable organs functional [184]. Similarly, induced neural cells may restore the memory in memory related diseases. For this purpose cell cycle machinery should be uplifted and continued for synchronizing differentiation of implanted tissues and its proliferation in recipients. Moreover, RA and Wnt signaling as key regulators of HSC development can provide new molecular insights for developing much advanced clinical therapeutics of disables [49] (Figures 7 and 8) (Table 1).

It will become a boon for those who lack fertility and show sexual disability generate functional ova or sperms. In such cases degenerated spermatocytes and ovarian follicles (Graffian follicles) could be replaced by functional gonadial progenitors. Certainly, it will not only help in generation of sexual capacity, but also heal various disorders related to cells of both sexes. Further, ovarian and testis explants grown in the laboratory can be implanted in the reproduction deficient couples. Certainly such implants may assist in generation of functional gametes. Thus by transplantation of regenerative tissues or 
Ravi Kant Upadhyay, Journal of Regenerative Medicine \& Tissue Engineering 2015,

http://www.hoajonline.com/journals/pdf/2050-1218-4-1.pdf

doi: $10.7243 / 2050-1218-4-1$

by doing organ transplants all possible ovarian or testicular collapses could be repaired for making them functional. This will prove boon for anatomically and physiologically incapable couples. Thus, complete restoration of estrus and menustrus cycles in both sexes could possible by hormone corrections. Moreover, stem cell based strategies would apply for ovarian regeneration and oocyte production in females, while in males it will restore spermatogenesis and testicular regeneration. No doubt both trans-differentiation and cytodifferentiation may help in generation of two different cell types by reprogramming.

\section{Conclusion}

Regenerative medicine is an inter-disciplinarily innovative research area which has wider applications in the field of oncology, embryology, immunology, physiology, cardiovascular, nephrology, anatomy and clinical biology mainly in organ and tissue transplantation. However, by applying biological and tissue engineering methods self-sustained growth of degenerated or injured organ tissues could be achieved. Truly regenerative tissue re-juvenation has provided life to millions of accidental disabled peoples. No doubt, limb regeneration and its replacement assisted millions of disables to walk or those who have faced accidents and bear brutal multiple injuries in limbs. Moreover, limb regeneration by somatic cell induction and tissue replacement therapies are proved boon for millions. Similarly, repairing of chronically ischemic muscles has provided a grand success in management of CLI (critical limb ischemia) patients. In addition, cases of acute sciatic traction injury could be solved by axial regeneration of nerve cell. It would be possible by unifying growth factors and gene activities more interactive in vivo. Further, cell programming and regenerative factors found in few animals like newts, axolotls and frogs can be used for clinical trials. Further, by applying positional memory as it occurs in fishes for formation of appendages can be used for evoking memory in degenerated tissues. It may start signaling in regeneration deficient regions and can restore any regenerative ability and may form new heads. Thus by studying the regenerative abilities of planarians and its molecular basis tissue injury restoration and healing of wounds in vertebrates are much possible. Conceptually cells identical in physiological and structural regeneration of membrane surfaces, ATP enzyme ports, signaling molecules involved in various pathways can be revitalized by using stem cells. However, minor and major cellular factors may evoke regeneration in deficient tissues by transplantation of most important genes, gene products and cells. Similarly, restoration of mitochondrial ATP production and use of artificially-generated cardiac muscles will be more useful in aged patients. These will also help in treatment of chronic respiratory dysfunction, cardiac related disorders, throat and esophageal problems, disease in the thorax. Further, by improving stem cell microenvironment, and applying combinatorial methods and molecules cell programming can be re-started in gonads of fertility deficient male and females of humans. Further, by supplying all transcription factors in settling micro-niche expansion of stem cells mainly iPs cells become possible for fertility restoration in females. Thus, stem cell transplantation will help to replace teratomas of gonads, brain, heart, thyroid, liver, lungs, and sensory organs. Similarly, physiological activity of tendons, spinal cord, ligaments, cartilages, skeletal muscles and cardiac muscles can be restored by generating regenerative tissue transplants. Further, precursors of fibroblasts can be used for $\mathrm{HSc}$ generation by functional expansion of naojan.

No doubt, regenerative medicine can fulfill the demand of shortage of organs for transplantation, and more disease free cell systems will made available for replacement therapies. It will need more advanced cell system studies that may provide better understanding about development of diseases, disorders and valuable insights for future clinical therapeutics of organ injuries whose repairing is impossible by using conventional drugs or by chemotherapeutics. Hence, for healing of defective or injured tissues need fine molecules and products, cells, and induction factors for regeneration of tissues in human body. Certainly by exploring molecular mechanisms of repair, replace, restore and regeneration will revitalize the therapeutic researches (Figure 9). Therefore, safer scaffold materials, cell systems, methods and technologies are essentially needed to find solution of clinical failures of cell and tissue transplantation. Further, formation of various cell fusion types will reduce the rate of tissue degeneration and will assist from many glandular infections. Conceptually cells identical in physiological and structural regeneration of membrane surfaces and body metabolism can change the therapeutic approach in case of cancer and tumor. Hence, biologically active molecules for immune-modulation and transplantation corrections in tissue grafts are to be identified. Further, promising candidate molecules such as immunomodulators, adhesions, integrins and new biological scaffold materials are used for tissue repairing and induction of regeneration in injured tissues. Further, role of various cells and its modifications in tissue engineering for phase specific repairing of tissues and induction of regeneration are to be explored. No doubt development of more advanced tissue transplantation methods based on cell regeneration programming and use of stem cell therapies will revolutionize the clinical therapeutics Such methods will be highly useful to identify mutual beneficial interest in field of developmental biology. No doubt, regenerative medicine is most emerging inter disciplinary field having high biological, clinical and socio-economic importance and is medicine of future. This innovative research area needs many conceptual improvements in neuronal and cardiovascular therapies.

\section{List of abbreviations}

TSPs: Transcription specific proteins 


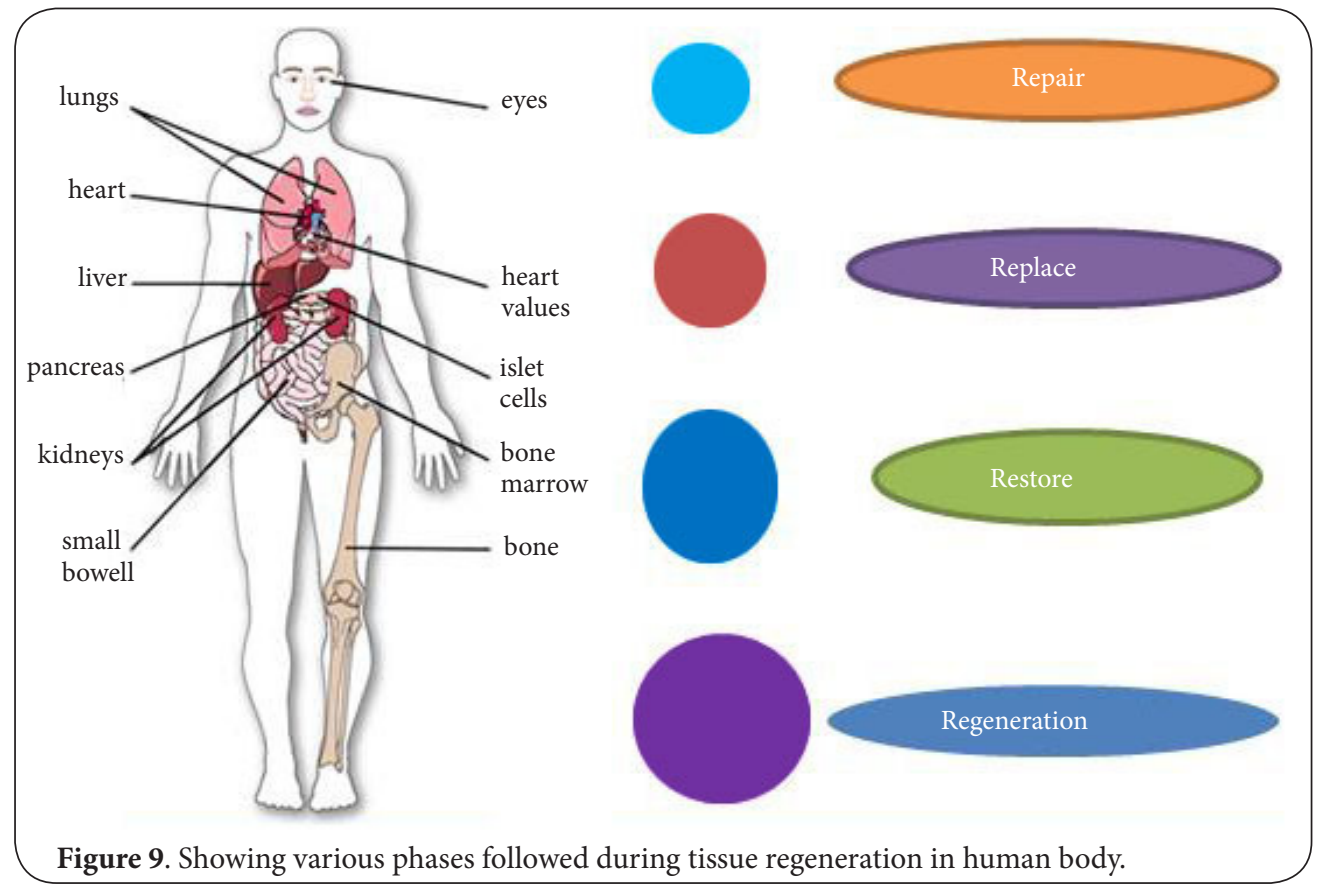

UCB: Umbilical cord blood

CNS: Central nervous system

SCs: Schwan cells

PSCs: Pluripotent stem cells

hESCs: pluripotent human embryonic stem cells

HSCs: Haematopoeitic stem cells

MSCs: Mesenchymal stem

ESCs: Embryonic stem cells

ECM: Extracellular

TREM: Tissue engineering and regenerative medicine

\section{Competing interests}

The author declares that he has no competing interests.

\section{Acknowledgement}

Author is thankful to university authorities for facilities provided.

\section{Publication history}

Editors: Anna Rita Migliaccio, Mount Sinai School of Medicine, USA. Juan Carlos Chachques, Paris University, France.

Received: 10-Apr-2015 Final Revised: 12-Jun-2015

Accepted: 23-Jul-2015 Published: 01-Aug-2015

\section{References}

1. Reinke JM and Sorg H. Wound repair and regeneration. Eur Surg Res. 2012; 49:35-43. | Article | PubMed

2. Spindler TJ, Tseng AW, Zhou X and Adams GB. Adipocytic cells augment the support of primitive hematopoietic cells in vitro but have no effect in the bone marrow niche under homeostatic conditions. Stem Cells Dev. 2014; 23:434-41. | Article | PubMed Abstract | PubMed Full $\underline{\text { Text }}$

3. Gilmore MA. Phases of wound healing. Dimens Oncol Nurs. 1991; 5:324. | Article | PubMed

4. Gokhale PJ and Andrews PW. Characterization of human pluripotent stem cells. Neuroreport. 2013; 24:1031-4. | Article | PubMed

5. Salgado AJ, Oliveira JM, Martins A, Teixeira FG, Silva NA, Neves NM, Sousa $N$ and Reis RL. Tissue engineering and regenerative medicine: past, present, and future. Int Rev Neurobiol. 2013; 108:1-33. | Article I PubMed

6. Martinod E, Seguin A, Radu DM, Boddaert G, Chouahnia K, FialaireLegendre A, Dutau H, Venissac N, Marquette CH, Baillard C, Valeyre D and Carpentier A. Airway transplantation: a challenge for regenerative medicine. Eur J Med Res. 2013; 18:25. | Article | PubMed Abstract | PubMed Full Text

7. Turner NJ, Keane TJ and Badylak SF. Lessons from developmental biology for regenerative medicine. Birth Defects Res C Embryo Today. 2013; 99:149-59. I PubMed

8. Bongso $A E$ and Turner $C$. Stem cells: their definition, classification and sources. Stem Cells: From Benchtop to Bedside. ed 2005; World Scientific. 5.

9. Gardner RL. Stem cells: potency, plasticity and public perception. J Anat. 2002; 200:277-82. | Article | PubMed Abstract | PubMed Full Text

10. Schöler HR. The Potential of Stem Cells: An Inventory. In Nikolaus Knoepffler, Dagmar Schipanski, and Stefan Lorenz Sorgner. 2007. Humanbiotechnology as Social Challenge. Ashgate Publishing. p. 28. ISBN 978-0-7546-5755-2.

11. Greenhough S and Hay DC. Stem Cell-Based Toxicity Screening: Recent Advances in Hepatocyte Generation. Pharm Med. 2012. 26:85-89. I Article

12. Faroni A, Terenghi $G$ and Reid AJ. Adipose-derived stem cells and nerve regeneration: promises and pitfalls. Int Rev Neurobiol. 2013; 108:12136. | Article | PubMed

13. Shostak S. Redefining stem cells. BioEssay. 2006; 28:301-8.

14. Iafolla MA, Tay J and Allan DS. Transplantation of umbilical cord bloodderived cells for novel indications in regenerative therapy or immune modulation: a scoping review of clinical studies. Biol Blood Marrow Transplant. 2014; 20:20-5. | Article | PubMed

15. Chotinantakul K, Prasajak $P$ and Leeanansaksiri W. Wnt1 Accelerates an Ex Vivo Expansion of Human Cord Blood CD34(+)CD38(-) Cells. Stem Cells Int. 2013; 2013:909812. | Article | PubMed Abstract | PubMed Full Text

16. Ungerer C, Quade-Lyssy P, Radeke HH, Henschler R, Konigs C, Kohl U, Seifried $E$ and Schuttrumpf J. Galectin-9 is a suppressor of T and B cells and predicts the immune modulatory potential of mesenchymal 
stromal cell preparations. Stem Cells Dev. 2014; 23:755-66. | Article | PubMed Abstract | PubMed Full Text

17. Pauklin $\mathrm{S}$ and Vallier $\mathrm{L}$. The cell-cycle state of stem cells determines cell fate propensity. Cell. 2013; 155:135-47. | Article | PubMed Abstract | PubMed Full Text

18. Jiang $Y$, Jahagirdar $B N$, Reinhardt RL, Schwartz RE, Keene $C D$, OrtizGonzalez XR, Reyes M, Lenvik T, Lund T, Blackstad M, Du J, Aldrich S, Lisberg A, Low WC, Largaespada DA and Verfaillie CM. Pluripotency of mesenchymal stem cells derived from adult marrow. Nature. 2002; 418:41-9. | Article | PubMed

19. Ratajczak MZ, Machalinski B, Wojakowski W, Ratajczak J and Kucia M. A hypothesis for an embryonic origin of pluripotent Oct- $4(+)$ stem cells in adult bone marrow and other tissues. Leukemia. 2007; 21:860-7. I Article I PubMed

20. Narasipura SD, Wojciechowski JC, Duffy BM, J LL and King MR. Purification of CD45+ hematopoietic cells directly from human bone marrow using a flow-based P-selectin-coated microtube. Am J Hematol. 2008; 83:627-9. | Article | PubMed

21. William JB, Prabakaran R and Ayyappan S. Functional Recovery of Spinal Cord Injury Following Application of Intralesional Bone Marrow Mononuclear Cells Embedded in Polymer Scaffold-Two Year Follow-up in a Canine. Journal of Stem Cell Research \& Therapy. 2011; 3. | Article

22. Terai S, Ishikawa T, Omori K, Aoyama K, Marumoto $\mathrm{Y}$, Urata $\mathrm{Y}$, Yokoyama Y, Uchida K, Yamasaki T, Fujii Y, Okita K and Sakaida I. Improved liver function in patients with liver cirrhosis after autologous bone marrow cell infusion therapy. Stem Cells. 2006; 24:2292-8. | Article | PubMed

23. Dedeepiya VD, Rao YY, Jayakrishnan GA, Parthiban JK, Baskar S, Manjunath SR, Senthilkumar R and Abraham SJ. Index of CD34+ Cells and Mononuclear Cells in the Bone Marrow of Spinal Cord Injury Patients of Different Age Groups: A Comparative Analysis. Bone Marrow Res. 2012; 2012:787414. | Article | PubMed Abstract | PubMed Full Text

24. Choi KW, Jeon WJ, Chae HB, Park SM, Youn SJ, Shin HM, Sung RH and Lee SJ. [A recurred case of a mature ovarian teratoma presenting as a rectal mass]. Korean J Gastroenterol. 2003; 42:242-5. | Pdf| PubMed

25. Kuno N, Kadomatsu K, Nakamura M, Miwa-Fukuchi T, Hirabayashi N and Ishizuka T. Ma ure ovarian cystic teratoma with a highly differentiated homunculus: a case report. Birth Defects in the retroperitoneum in a child: is a mature teratoma a premalignant condition? Hum. Research. Part a, Clinical and Molecular Teratology. 2004; 70:40-6.

26. Ohno $Y$ and Kanematsu $T$. An endodermal sinus tumor arising from a mature cystic teratoma in the retroperitoneum in a child: is a mature teratoma a premalignant condition? Hum Pathol. 1998; 29:1167-9. | Article I PubMed

27. Arioz DT, Tokyol C, Sahin FK, Koker G, Yilmaz S, Yilmazer M and Ozalp S. Squamous cell carcinoma arising in a mature cystic teratoma of the ovary in young patient with elevated carbohydrate antigen 19-9. Eur J Gynaecol Oncol. 2008; 29:282-4. I PubMed

28. Harms D, Zahn S, Gobel U and Schneider DT. Pathology and molecular biology of teratomas in childhood and adolescence. Klin Padiatr. 2006; 218:296-302. | Article | PubMed

29. Gonzalez -Crussi. Extragonadal Teratomas. Atlas of Tumor Pathology, Second Series. Fascicle 18. Armed Forces Institute of Pathology, Washington D.C. 1982.

30. Kazez A, Ozercan IH, Erol FS, Faik Ozveren M and Parmaksiz E. Sacrococcygeal heart: a very rare differentiation in teratoma. Eur J Pediatr Surg. 2002; 12:278-80. | Article | PubMed

31. Muscatello L, Giudice $M$ and Feltri M. Malignant cervical teratoma: report of a case in a newborn. Eur Arch Otorhinolaryngol. 2005; 262:899-904. | Article | PubMed

32. Gobel U, Schneider DT, Calaminus G, Haas RJ, Schmidt P and Harms D. Germ-cell tumors in childhood and adolescence. GPOH MAKEI and the MAHO study groups. Ann Oncol. 2000; 11:263-71. | Article | PubMed

33. Lopez RM and Murcia DB. First description of malignant retrobulbar and intracranial teratoma in a lesser kestrel (Falco naumanni). Avian Pathol. 2008; 37:413-4. | Article | PubMed
34. Mitalipov $S$ and Wolf D. Totipotency, pluripotency and nuclear reprogramming. Adv Biochem Eng Biotechnol. 2009; 114:185-99. | Article | PubMed Abstract | PubMed Full Text

35. Lu $X$ and Zhao T. Clinical therapy using iPSCs: hopes and challenges. Genomics Proteomics Bioinformatics. 2013; 11:294-8. | Article | PubMed Abstract | PubMed Full Text

36. Ulloa-Montoya F, Verfaillie $\mathrm{CM}$ and Hu WS. Culture systems for pluripotent stem cells. J Biosci Bioeng. 2005; 100:12-27. | Article | PubMed

37. Ishiuchi T and Torres-Padilla ME. Towards an understanding of the regulatory mechanisms of totipotency. Curr Opin Genet Dev. 2013; 23:512-8. | Article | PubMed

38. Subrammaniyan R, Amalorpavanathan J, Shankar R, Rajkumar M, Baskar S, Manjunath SR, Senthilkumar R, Murugan P, Srinivasan VR and Abraham S. Application of autologous bone marrow mononuclear cells in six patients with advanced chronic critical limb ischemia as a result of diabetes: our experience. Cytotherapy. 2011; 13:993-9. | Article I PubMed

39. Madhusankar N, Vaidyanathan K, Rajesh V, Prasad G, Kirtivasan V, Naveen A, Abraham S and Cherian K. Use of Bone Marrow derived Stem Cells in Patients with Cardiovascular Disorders. J Stem Cells Regen Med. 2007; 3:28-9. | PubMed

40. Wang J, Gu Q, Hao J, Bai D, Liu L, Zhao X, Liu Z, Wang L and Zhou Q. Generation of induced pluripotent stem cells with high efficiency from human umbilical cord blood mononuclear cells. Genomics Proteomics Bioinformatics. 2013; 11:304-11. | Article | PubMed Abstract | PubMed Full Text

41. Barrilleaux B, Phinney DG, Prockop DJ and O'Connor KC. Review: ex vivo engineering of living tissues with adult stem cells. Tissue Eng. 2006; 12:3007-19. | Article | PubMed

42. Gimble JM, Katz AJ and Bunnell BA. Aipose-derived stem cells for regenerative medicine. Circ Res. 2007; 100: 1249-60. | Article

43. Gahrton $G$ and Bjorkstrand B. Progress in haematopoietic stem cell transplantation for multiple myeloma. J Intern Med. 2000; 248:185201. | Article | PubMed

44. Huang GT, Gronthos S and Shi S. Mesenchymal stem cells derived from dental tissues vs. those from other sources: their biology and role in regenerative medicine. J Dent Res. 2009; 88:792-806. | Article | PubMed Abstract | PubMed Full Text

45. Kane Ed. Stem-cell therapy shows promise for horse soft-tissue injury, disease. DVM Newsmagazine. 2008.

46. Pakzad M, Ashtiani MK, Mousavi-Gargari SL and Baharvand $\mathrm{H}$. Development of a simple, repeatable, and cost-effective extracellular matrix for long-term xeno-free and feeder-free self-renewal of human pluripotent stem cells. Histochem Cell Biol. 2013; 140:635-48. | Article | PubMed

47. Zhang XB. Cellular reprogramming of human peripheral blood cells Genomics Proteomics Bioinformatics. 2013; 11:264-74. | Article | PubMed Abstract | PubMed Full Text

48. Bakker ST and Passegue E. Resilient and resourceful: genome maintenance strategies in hematopoietic stem cells. Exp Hematol. 2013; 41:915-23. | Article | PubMed Abstract | PubMed Full Text

49. Chanda B, Ditadi A, Iscove NN and Keller G. Retinoic acid signaling is essential for embryonic hematopoietic stem cell development. Cell. 2013; 155:215-27. | Article | PubMed

50. Kaczorowski CC, Stodola TJ, Hoffmann BR, Prisco AR, Liu PY, Didier DN, Karcher JR, Liang M, Jacob HJ and Greene AS. Targeting the endothelial progenitor cell surface proteome to identify novel mechanisms that mediate angiogenic efficacy in a rodent model of vascular disease. Physiol Genomics. 2013; 45:999-1011. | Article | PubMed Abstract | PubMed Full Text

51. Horai N, Nagaoka T, Higuchi I, Kasai H, Yoshioka T, Umekita Y, Fukuzaki K, Nagata R, Miyata A and Abeyama K. Muscle wasting associated with pathologic change is a risk factor for the exacerbation of joint swelling in collagen-induced arthritis in cynomolgus monkeys. BMC Musculoskelet Disord. 2013; 14:205. | Article | PubMed Abstract | PubMed Full Text 
52. Attia WA, Abd El Aziz OM, Spitkovsky D, Gaspar JA, Droge P, Suhr F, Sabour D, Winkler J, Meganathan K, Jagtap S, Khalil M, Hescheler J, Konrad B, Agapios S and Kurt P. Evidence for self-maintaining pluripotent murine stem cells in embryoid bodies. Stem Cell Rev. 2014; 10:1-15. | Article | PubMed

53. Zhao $\mathrm{Y}, \mathrm{Wang} \mathrm{H}$ and Mazzone $\mathrm{T}$. Identification of stem cells from human umbilical cord blood with embryonic and hematopoietic characteristics. Exp Cell Res. 2006; 312:2454-64. | Article I PubMed

54. Yu J, Vodyanik MA, Smuga-Otto K, Antosiewicz-Bourget J, Frane JL, Tian S, Nie J, Jonsdottir GA, Ruotti V, Stewart R, Slukvin, II and Thomson JA. Induced pluripotent stem cell lines derived from human somatic cells. Science. 2007; 318:1917-20. | Article | PubMed

55. Aoi T, Yae K, Nakagawa M, Ichisaka T, Okita K, Takahashi K, Chiba T and Yamanaka S. Generation of pluripotent stem cells from adult mouse liver and stomach cells. Science. 2008; 321:699-702. | Article | PubMed

56. Conrad S, Renninger M, Hennenlotter J, Wiesner T, Just $L$, Bonin $M$, Aicher W, Buhring HJ, Mattheus U, Mack A, Wagner HJ, Minger S, Matzkies M, Reppel M, Hescheler J, Sievert KD, Stenzl A and Skutella T. Generation of pluripotent stem cells from adult human testis. Nature. 2008; 456:344-9. | Article I PubMed

57. Takahashi K, Tanabe K, Ohnuki M, Narita M, Ichisaka T, Tomoda K and Yamanaka S. Induction of pluripotent stem cells from adult human fibroblasts by defined factors. Cell. 2007; 131:861-72. | Article | PubMed

58. Wahlestedt M, Norddahl GL, Sten G, Ugale A, Frisk MA, Mattsson R, Deierborg T, Sigvardsson M and Bryder D. An epigenetic component of hematopoietic stem cell aging amenable to reprogramming into a young state. Blood. 2013; 121:4257-64. | $\underline{\text { Article | PubMed }}$

59. Friedenstein AJ, Deriglasova UF, Kulagina NN, Panasuk AF, Rudakowa SF, Luria EA and Ruadkow IA. Precursors for fibroblasts in different populations of hematopoietic cells as detected by the in vitro colony assay method. Exp Hematol. 1974; 2:83-92. I PubMed

60. Friedenstein AJ, Gorskaja JF and Kulagina NN. Fibroblast precursors in normal and irradiated mouse hematopoietic organs. Exp Hematol. 1976; 4:267-74. | Article | PubMed

61. Chen WC, Park TS, Murray IR, Zimmerlin L, Lazzari L, Huard J and Peault B. Cellular kinetics of perivascular MSC precursors. Stem Cells Int. 2013; 2013:983059. | Article | PubMed Abstract | PubMed Full Text

62. Di Tomo P, Pipino C, Lanuti P, Morabito C, Pierdomenico L, Sirolli V, Bonomini M, Miscia S, Mariggio MA, Marchisio M, Barboni B and Pandolfi A. Calcium sensing receptor expression in ovine amniotic fluid mesenchymal stem cells and the potential role of R-568 during osteogenic differentiation. PLoS One. 2013; 8:e73816. | Article | PubMed Abstract | PubMed Full Text

63. Kawaguchi N, Hatta $\mathrm{K}$ and Nakanishi T. 3D-culture system for heart regeneration and cardiac medicine. Biomed Res Int. 2013, 2013:895967. | Article | PubMed Abstract | PubMed Full Text

64. Balmayor ER, Flicker M, Kaser T, Saalmuller A and Erben RG. Human placental alkaline phosphatase as a tracking marker for bone marrow mesenchymal stem cells. Biores Open Access. 2013; 2:346-55. I Article | PubMed Abstract | PubMed Full Text

65. Mishra PK, Kuypers NJ, Singh SR, Leiberh ND, Chavali V and Tyagi SC. Cardiac stem cell niche, MMP9, and culture and differentiation of embryonic stem cells. Methods Mol Biol. 2013; 1035:153-63. | Article I PubMed

66. Morgani SM, Canham MA, Nichols J, Sharov AA, Migueles RP, Ko MS and Brickman JM. Totipotent embryonic stem cells arise in groundstate culture conditions. Cell Rep. 2013; 3:1945-57. | Article | PubMed Abstract I PubMed Full Text

67. New Stem-Cell Procedure Doesn't Harm Embryos. Company Claims. Associated Press via Fox News. 2006.

68. Xi G, Hu P, Qu C, Qiu S, Tong C and Ying QL. Induced neural stem cells generated from rat fibroblasts. Genomics Proteomics Bioinformatics. 2013; 11:312-9. | Article | PubMed Abstract | PubMed Full Text

69. Wu M, Chen $\mathrm{G}$ and Hu B. Induced pluripotency for translational research. Genomics Proteomics Bioinformatics. 2013; 11:288-93. Article | PubMed Abstract | PubMed Full Text

70. Culture of Human Embryonic Stem Cells (hESC). National Institutes of Health. 2010.

71. Chambers I, Colby D, Robertson M, Nichols J, Lee S, Tweedie S and Smith A. Functional expression cloning of Nanog, a pluripotency sustaining factor in embryonic stem cells. Cell. 2003; 113:643-55. | Article I PubMed

72. Keirstead HS, Nistor G, Bernal G, Totoiu M, Cloutier F, Sharp K and Steward $O$. Human embryonic stem cell-derived oligodendrocyte progenitor cell transplants remyelinate and restore locomotion after spinal cord injury. J Neurosci. 2005; 25:4694-705. I Article I PubMed

73. Adewumi O, Aflatoonian B, Ahrlund-Richter L, Amit M, Andrews PW, Beighton G, Bello PA, Benvenisty N, Berry LS and Bevan S et al. Characterization of human embryonic stem cell lines by the International Stem Cell Initiative. Nat Biotechnol. 2007; 25:803-16. | Article I PubMed

74. Chung Y, Klimanskaya I, Becker S, Li T, Maserati M, Lu SJ, Zdravkovic T, Ilic D, Genbacev O, Fisher S, Krtolica A and Lanza R. Human embryonic stem cell lines generated without embryo destruction. Cell Stem Cell. 2008; 2:113-7. I Article | PubMed

75. Thomson JA, Itskovitz-Eldor J, Shapiro SS, Waknitz MA, Swiergiel JJ, Marshall VS and Jones JM. Embryonic stem cell lines derived from human blastocysts. Science. 1998; 282:1145-7. I Article I PubMed

76. Brand M, Palca J and Cohen A. Skin Cells Can Become Embryonic Stem Cells. National Public Radio. 2007.

77. Baker M. Embryonic-like stem cells from a single human hair. Nature Reports Stem Cells. 2008.

78. Cyranoski D. Simple switch turns cells embryonic. Nature. 2007; 447:618-9. | Article I PubMed

79. Brafman DA, Phung C, Kumar N and Willert K. Regulation of endodermal differentiation of human embryonic stem cells through integrin-ECM interactions. Cell Death Differ. 2013; 20:369-81. | Article | PubMed Abstract | PubMed Full Text

80. Boyer LA, Lee TI, Cole MF, Johnstone SE, Levine SS, Zucker JP, Guenther MG, Kumar RM, Murray HL, Jenner RG, Gifford DK, Melton DA, Jaenisch $\mathrm{R}$ and Young RA. Core transcriptional regulatory circuitry in human embryonic stem cells. Cell. 2005; 122:947-56. I Article I PubMed Abstract I PubMed Full Text

81. Corona BT, Ward CL, Baker HB, Walters TJ and Christ GJ. Implantation of in vitro tissue engineered muscle repair constructs and bladder acellular matrices partially restore in vivo skeletal muscle function in a rat model of volumetric muscle loss injury. Tissue Eng Part A. 2014; 20:705-15. I Article I PubMed

82. Wan AC and Tai BC. CHITIN--a promising biomaterial for tissue engineering and stem cell technologies. Biotechnol Adv. 2013; 31:1776-85. | Article | PubMed

83. Teuschl $A H$, van Griensven $M$ and Redl $H$. Sericin removal from raw Bombyx mori silk scaffolds of high hierarchical order. Tissue Eng Part $C$ Methods. 2014; 20:431-9. I Article | PubMed

84. Labusca $L$ and Mashayekhi K. Adipose-derived stem cells for cartilage regeneration--moving towards clinical applicability. Stem Cell Res Ther. 2013; 4:118. I Article | PubMed Abstract I PubMed Full Text

85. See EY, Kulkarni M and Pandit A. Regeneration of the limb: opinions on the reality. J Mater Sci Mater Med. 2013; 24:2627-33. I Article I PubMed

86. Yang Z, Hai B, Qin L, Ti X, Shangguan L, Zhao Y, Wiggins L, Liu Y, Feng JQ, Chang JY, Wang F and Liu F. Cessation of epithelial Bmp signaling switches the differentiation of crown epithelia to the root lineage in a beta-catenin-dependent manner. Mol Cell Biol. 2013; 33:4732-44. | Article I PubMed Abstract | PubMed Full Text

87. Lin Z, Fateh A, Salem DM and Intini G. Periosteum: biology and applications in craniofacial bone regeneration. J Dent Res. 2014; 93:109-16. | Article | PubMed Abstract | PubMed Full Text

88. Xiong JW and Chang NN. Recent advances in heart regeneration. Birth Defects Res C Embryo Today. 2013; 99:160-9. I Article I PubMed 
89. Corum DG, Tsichlis PN and Muise-Helmericks RC. AKT3 controls mitochondrial biogenesis and autophagy via regulation of the major nuclear export protein CRM-1. FASEB J. 2014; 28:395-407. | Article | PubMed Abstract | PubMed Full Text

90. Tiwari A, Hadley JA, Hendricks GL, 3rd, Elkin RG, Cooper T and Ramachandran R. Characterization of ascites-derived ovarian tumor cells from spontaneously occurring ovarian tumors of the chicken: evidence for E-cadherin upregulation. PLoS One. 2013; 8:e57582. | Article I PubMed Abstract I PubMed Full Text

91. Zhao $Y$ and Mazzone T. Human cord blood stem cells and the journey to a cure for type 1 diabetes. Autoimmun Rev. 2010; 10:103-7. | Article I PubMed

92. Zhao $Y$, Jiang Z, Zhao T, Ye M, Hu C, Yin Z, Li H, Zhang Y, Diao Y, Li Y, Chen $Y$, Sun X, Fisk MB, Skidgel R, Holterman M, Prabhakar B and Mazzone T. Reversal of type 1 diabetes via islet beta cell regeneration following immune modulation by cord blood-derived multipotent stem cells. BMC Med. 2012; 10:3. | Article | PubMed Abstract | PubMed Full Text

93. Zhao $Y$, Lin B, Dingeldein M, Guo C, Hwang D and Holterman MJ. New type of human blood stem cell: a double-edged sword for the treatment of type 1 diabetes. Transl Res. 2010; 155:211-6. | Article | PubMed

94. Zhao $Y$, Lin B, Darflinger R, Zhang $Y$, Holterman MJ and Skidgel RA. Human cord blood stem cell-modulated regulatory T lymphocytes reverse the autoimmune-caused type 1 diabetes in nonobese diabetic (NOD) mice. PLoS One. 2009; 4:e4226. | Article | PubMed Abstract | PubMed Full Text

95. Tiwari A, Hadley JA, Hendricks GL, 3rd, Elkin RG, Cooper T and Ramachandran R. Characterization of ascites-derived ovarian tumor cells from spontaneously occurring ovarian tumors of the chicken: evidence for E-cadherin upregulation. PLoS One. 2013; 8:e57582. | Article I PubMed Abstract I PubMed Full Text

96. Xiong JW and Chang NN. Recent advances in heart regeneration. Birth Defects Res C Embryo Today. 2013; 99:160-9. | PubMed

97. Gahrton $\mathrm{G}$ and Bjorkstrand B. Progress in haematopoietic stem cell transplantation for multiple myeloma. J Intern Med. 2000; 248:185201. | Article | PubMed

98. Strauer BE, Schannwell CM and Brehm M. Therapeutic potentials of stem cells in cardiac diseases. Minerva Cardioangiol. 2009; 57:249-67. | Article | PubMed

99. Lindvall O. Stem cells for cell therapy in Parkinson's disease. Pharmacol Res. 2003; 47:279-87. | Article | PubMed

100. Goldman SA and Windrem MS. Cell replacement therapy in neurological disease. Philos Trans R Soc Lond B Biol Sci. 2006; 361:1463-75. | Article | PubMed Abstract | PubMed Full Text

101. Zhao $Y$, Huang Z, Qi M, Lazzarini $P$ and Mazzone T. Immune regulation of T lymphocyte by a newly characterized human umbilical cord blood stem cell. Immunol Lett. 2007; 108:78-87. | Article | PubMed

102. Corum DG, Tsichlis PN and Muise-Helmericks RC. AKT3 controls mitochondrial biogenesis and autophagy via regulation of the major nuclear export protein CRM-1. FASEB J. 2014; 28:395-407. | Article | PubMed Abstract I PubMed Full Text

103. Marshall $B T$, Ingraham CA, Wu $X$ and Washenik K. Future horizons in hair restoration. Facial Plast Surg Clin North Am. 2013; 21:521-8. | Article I PubMed

104. Leung Y, Kandyba E, Chen YB, Ruffins S and Kobielak K. Label retaining cells (LRCs) with myoepithelial characteristic from the proximal acinar region define stem cells in the sweat gland. PLoS One. 2013; 8:e74174. | Article | PubMed Abstract | PubMed Full Text

105. Lim ML, Jungebluth $P$, Ajalloueian F, Friedrich LH, Gilevich I, Grinnemo KH, Gubareva E, Haag JC, Lemon G, Sjoqvist S, Caplan AL and Macchiarini $P$. Whole organ and tissue reconstruction in thoracic regenerative surgery. Mayo Clin Proc. 2013; 88:1151-66. | Article | PubMed

106. Vierbuchen T, Ostermeier A, Pang ZP, Kokubu Y, Sudhof TC and Wernig $M$. Direct conversion of fibroblasts to functional neurons by defined factors. Nature. 2010; 463:1035-41. | Article | PubMed Abstract | PubMed Full Text
107. Stojadinovic $O$ and Tomic-Canic M. Human ex vivo wound healing model. Methods Mol Biol. 2013; 1037:255-64. | Article | PubMed

108. Maxson S, Lopez EA, Yoo D, Danilkovitch-Miagkova A and Leroux MA. Concise review: role of mesenchymal stem cells in wound repair. Stem Cells Trans/ Med. 2012; 1:142-9. | Article | PubMed Abstract | PubMed Full Text

109. Romo T, Al Moutran H, Pearson JM, Yalamanchili H, Pafford W and Zoumalan RA. Skin Wound Healing. Medscape Reference. 2012

110. Meier NT, Haslam IS, Pattwell DM, Zhang GY, Emelianov V, Paredes R, Debus S, Augustin M, Funk W, Amaya E, Kloepper JE, Hardman MJ and Paus R. Thyrotropin-releasing hormone (TRH) promotes wound reepithelialisation in frog and human skin. PLoS One. 2013; 8:e73596. Article I PubMed Abstract | PubMed Full Text

111. Yang G, Rothrauff BB and Tuan RS. Tendon and ligament regeneration and repair: clinical relevance and developmental paradigm. Birth Defects Res C Embryo Today. 2013; 99:203-22. | Article | PubMed Abstract I PubMed Full Text

112. Yang Z, Hai B, Qin L, Ti X, Shangguan L, Zhao Y, Wiggins L, Liu Y, Feng $J Q$, Chang JY, Wang F and Liu F. Cessation of epithelial Bmp signaling switches the differentiation of crown epithelia to the root lineage in a beta-catenin-dependent manner. Mol Cell Biol. 2013; 33:4732-44. I Article I PubMed Abstract I PubMed Full Text

113. Kew SJ, Gwynne JH, Enea D, Abu-Rub M, Pandit A, Zeugolis D, Brooks RA, Rushton N, Best SM and Cameron RE. Regeneration and repair of tendon and ligament tissue using collagen fibre biomaterials. Acta Biomater. 2011; 7:3237-47. | Article | PubMed Abstract

114. Stevanovic V, Blagojevic Z, Petkovic A, Glisic M, Sopta J, Nikolic V and Milisavljevic M. Semitendinosus tendon regeneration after anterior cruciate ligament reconstruction: can we use it twice? Int Orthop. 2013; 37:2475-81. | Article | PubMed Abstract | PubMed Full Text

115. Mizuno M, Kobayashi S, Takebe T, Kan H, Yabuki Y, Matsuzaki T, Yoshikawa HY, Nakabayashi S, Ik LJ, Maegawa J and Taniguchi H. Brief report: reconstruction of joint hyaline cartilage by autologous progenitor cells derived from ear elastic cartilage. Stem Cells. 2014; 32:816-21. | Article | PubMed

116. Lee JK, Responte DJ, Cissell DD, Hu JC, Nolta JA and Athanasiou KA. Clinical translation of stem cells: insight for cartilage therapies. Crit Rev Biotechnol. 2014; 34:89-100. | Article | PubMed Abstract | PubMed Full Text

117. Saito T, Yano F, Mori D, Ohba S, Hojo H, Otsu M, Eto K, Nakauchi $H$, Tanaka S, Chung UI and Kawaguchi H. Generation of Col2a1-EGFP iPS cells for monitoring chondrogenic differentiation. PLoS One. 2013; 8:e74137. | Article | PubMed Abstract | PubMed Full Text

118. Iwamoto $\mathrm{M}$, Ohta $\mathrm{Y}$, Larmour $\mathrm{C}$ and Enomoto-Iwamoto $\mathrm{M}$. Toward regeneration of articular cartilage. Birth Defects Res C Embryo Today. 2013; 99:192-202. | Article | PubMed Abstract | PubMed Full Text

119. Centeno CJ, Busse D, Kisiday J, Keohan C, Freeman M and Karli D. Increased knee cartilage volume in degenerative joint disease using percutaneously implanted, autologous mesenchymal stem cells. Pain Physician. 2008; 11:343-53. | PubMed

120. Andia I and Maffulli N. Platelet-rich plasma for managing pain and inflammation in osteoarthritis. Nat Rev Rheumatol. 2013; 9:721-30. | Article I PubMed

121. Windahl SH, Borjesson AE, Farman HH, Engdahl C, Moverare-Skrtic S, Sjogren K, Lagerquist MK, Kindblom JM, Koskela A, Tuukkanen J, Divieti Pajevic P, Feng JQ, Dahlman-Wright K, Antonson P, Gustafsson $J A$ and Ohlsson C. Estrogen receptor-alpha in osteocytes is important for trabecular bone formation in male mice. Proc Natl Acad Sci U S A. 2013; 110:2294-9. | Article | PubMed Abstract | PubMed Full Text

122. See EY, Kulkarni M and Pandit A. Regeneration of the limb: opinions on the reality. J Mater Sci Mater Med. 2013; 24:2627-33. | Article | PubMed

123. Ratner BD. Going out on a limb about regrowing an arm. J Mater Sci Mater Med. 2013; 24:2645-9. | Article | PubMed

124. Huang C, Jackson M, Samuel K, Taylor AH, Lowell S and Forrester LM. Haematopoietic differentiation is inhibited when Notch activity is enhanced in FLK1 ${ }^{+}$mesoderm progenitors. Stem Cell Res. 2012; 


\section{1:1273-1287. | Article}

125. Cunha FF, Martins L, Martin PK, Stilhano RS and Han SW. A comparison of the reparative and angiogenic properties of mesenchymal stem cells derived from the bone marrow of BALB/C and C57/BL6 mice in a model of limb ischemia. Stem Cell Res Ther. 2013; 4:86. | Article | PubMed Abstract | PubMed Full Text

126. Li G and Liu Z. [Treatment of long bone fracture nonunion in limbs by bone morphogenetic protein compounds combined with autologous red bone marrow graft]. Zhongguo Gu Shang. 2013; 26:277-80. | PubMed

127. N. Horai, T. Nagaoka , I. Higuchi, H. Kasai, T. Yoshioka, Y. Umekita and Z $\mathrm{K}$. Fukuzaki, et al. Muscle wasting associated with pathologic change is a risk factor for the exacerbation of joint swelling in collagen-induced arthritis in cynomolgus monkeys. BMC Musculoskelet Disord. 2013; 14:205. | Article

128. T. Horii, D. Tamura, S. Morita, M. Kimura, and Z I. Hatada. Generation of an ICF Syndrome Model by Efficient Genome Editing of Human Induced Pluripotent Stem Cells Using the CRISPR System. Int J Mol Sci. 2013; 14:19774-19781. | Article

129. Sikes JM and Newmark PA. Restoration of anterior regeneration in a planarian with limited regenerative ability. Nature. 2013; 500:77-80. | Article | PubMed Abstract | PubMed Full Text

130. Burns G, Thorndyke MC, Peck LS and Clark MS. Transcriptome pyrosequencing of the Antarctic brittle star Ophionotus victoriae. Mar Genomics. 2013; 9:9-15. | Article | PubMed

131. Simon A and Tanaka EM. Limb regeneration. Wiley Interdiscip Rev Dev Biol. 2013; 2:291-300. | Article | PubMed

132. Nachtrab G, Kikuchi K, Tornini VA and Poss KD. Transcriptional components of anteroposterior positional information during zebrafish fin regeneration. Development. 2013; 140:3754-64. | Article | PubMed Abstract | PubMed Full Text

133. Kim SW, Youn S, Kim JD, Kim JT, Hwang KT and Kim YH. Reconstruction of extensive lower limb defects with thoracodorsal axis chimeric flaps. Plast Reconstr Surg. 2013; 132:470-9. I Article I PubMed

134. Yablonka-Reuveni $Z$. The skeletal muscle satellite cell: still young and fascinating at 50. J Histochem Cytochem. 2011; 59:1041-59. | Article | PubMed Abstract | PubMed Full Text

135. Chiu RC, Zibaitis A and Kao RL. Cellular cardiomyoplasty: myocardial regeneration with satellite cell implantation. Ann Thorac Surg. 1995; 60:12-8. | PubMed

136. Koh GY, Klug MG, Soonpaa MH and Field LJ. Differentiation and longterm survival of C2C12 myoblast grafts in heart. J Clin Invest. 1993; 92:1548-54. | Article | PubMed Abstract | PubMed Full Text

137. Murry CE, Wiseman RW, Schwartz SM and Hauschka SD. Skeletal myoblast transplantation for repair of myocardial necrosis. J Clin Invest. 1996; 98:2512-23. | Article | PubMed Abstract | PubMed Full Text

138. Reinecke $H$, Poppa $V$ and Murry CE. Skeletal muscle stem cells do not transdifferentiate into cardiomyocytes after cardiac grafting. I Mol Cell Cardiol. 2002; 34:241-9. | Article | PubMed

139. Reinecke H, Minami E, Poppa V and Murry CE. Evidence for fusion between cardiac and skeletal muscle cells. Circ Res. 2004; 94:e56-60. | Article | PubMed

140. Scorsin M, Hagege A, Vilquin JT, Fiszman M, Marotte F, Samuel JL, Rappaport L, Schwartz K and Menasche P. Comparison of the effects of fetal cardiomyocyte and skeletal myoblast transplantation on postinfarction left ventricular function. J Thorac Cardiovasc Surg. 2000; 119:1169-75. | Article | PubMed

141. Hutcheson KA, Atkins BZ, Hueman MT, Hopkins MB, Glower DD and Taylor DA. Comparison of benefits on myocardial performance of cellular cardiomyoplasty with skeletal myoblasts and fibroblasts. Cell Transplant. 2000; 9:359-68. | PubMed

142. Soonpaa MH, Koh GY, Klug MG and Field LJ. Formation of nascent intercalated disks between grafted fetal cardiomyocytes and host myocardium. Science. 1994; 264:98-101. | Article | PubMed

143. Durrani S, Konoplyannikov M, Ashraf M and Haider KH. Skeletal myoblasts for cardiac repair. Regen Med. 2010; 5:919-32. | Article | PubMed Abstract | PubMed Full Text

144. Lui KO, Zangi L, Silva EA, Bu L, Sahara M, Li RA, Mooney DJ and Chien KR. Driving vascular endothelial cell fate of human multipotent IsI1+ heart progenitors with VEGF modified mRNA. Cell Res. 2013; 23:117286. | Article | PubMed Abstract | PubMed Full Text

145. Yano M, Kawao N, Tamura Y, Okada K and Kaji H. A novel factor, Tmem176b, induced by activin-like kinase 2 signal promotes the differentiation of myoblasts into osteoblasts. Exp Clin Endocrinol Diabetes. 2014; 122:7-14. | Article | PubMed

146. Lee JK, Responte DJ, Cissell DD, Hu JC, Nolta JA and Athanasiou KA. Clinical translation of stem cells: insight for cartilage therapies. Crit Rev Biotechnol. 2014; 34:89-100. | Article | PubMed Abstract | PubMed Full Text

147. Muraoka $\mathrm{N}$ and leda $\mathrm{M}$. Direct reprogramming of fibroblasts into myocytes to reverse fibrosis. Annu Rev Physiol. 2014; 76:21-37. | Article | PubMed

148. Qian L and Srivastava D. Direct cardiac reprogramming: from developmental biology to cardiac regeneration. Circ Res. 2013; 113:915-21. | Article | PubMed Abstract | PubMed Full Text

149. Nagura S, Otaka S, Koike C, Okabe M, Yoshida T, Fathy M, Fukahara K, Yoshimura N, Misaki T and Nikaido T. Effect of exogenous Oct4 overexpression on cardiomyocyte differentiation of human amniotic mesenchymal cells. Cell Reprogram. 2013; 15:471-80. | Article | PubMed

150. Liu BW, Lu AL, Hou J, Huang W, Hou H, Hou ZL, Da J and Ai SY. Electrophysiological characteristics of cardiomyocyte-like cells from rat bone marrow derived mesenchymal stem cells by four inductors. Chin Med J (Engl). 2013; 126:3528-33. | PubMed

151. Xiong JW and Chang NN. Recent advances in heart regeneration. Birth Defects Res C Embryo Today. 2013; 99:160-9. | Article | PubMed

152. Strungs EG, Ongstad EL, O'Quinn MP, Palatinus JA, Jourdan LJ and Gourdie RG. Cryoinjury models of the adult and neonatal mouse heart for studies of scarring and regeneration. Methods Mol Biol. 2013; 1037:343-53. | Article | PubMed

153. Dickover MS, Zhang R, Han P and Chi NC. Zebrafish cardiac injury and regeneration models: a noninvasive and invasive in vivo model of cardiac regeneration. Methods Mol Biol. 2013; 1037:463-73. | Article | PubMed Abstract I PubMed Full Text

154. Targoff KL, Colombo S, George V, Schell T, Kim SH, Solnica-Krezel L and Yelon D. Nkx genes are essential for maintenance of ventricular identity. Development. 2013; 140:4203-13. | Article | PubMed Abstract I PubMed Full Text

155. Martinez-Fernandez A, Li X, Hartjes KA, Terzic A and Nelson TJ. Natural cardiogenesis-based template predicts cardiogenic potential of induced pluripotent stem cell lines. Circ Cardiovasc Genet. 2013; 6:462-71. | Article | PubMed Abstract | PubMed Full Text

156. Strauer BE, Schannwell CM and Brehm M. Therapeutic potentials of stem cells in cardiac diseases. Minerva Cardioangiol. 2009; 57:249-67. | Article | PubMed

157. Reshak AH, Shahimin MM and Buang F. Comparative study on human and bovine AT-SC isolation methods. Prog Biophys Mol Biol. 2013; 113:295-8. | Article | PubMed

158. Shoham N, Sasson AL, Lin FH, Benayahu D, Haj-Ali R and Gefen A. The mechanics of hyaluronic acid/adipic acid dihydrazide hydrogel: towards developing a vessel for delivery of preadipocytes to native tissues. J Mech Behav Biomed Mater. 2013; 28:320-31. | Article | PubMed

159. Labusca $L$ and Mashayekhi K. Adipose-derived stem cells for cartilage regeneration--moving towards clinical applicability. Stem Cell Res Ther. 2013; 4:118. | Article | PubMed Abstract | PubMed Full Text

160. Li J, Qiao X, Yu M, Li F, Wang H, Guo W and Tian W. Secretory factors from rat adipose tissue explants promote adipogenesis and angiogenesis. Artif Organs. 2014; 38:E33-45. | Article | PubMed

161. Woods DC and Tilly JL. The next (re)generation of ovarian biology and fertility in women: is current science tomorrow's practice? Fertil Steril. 2012; 98:3-10. | Article | PubMed Abstract | PubMed Full Text 
162. Cao Y, Fu YL, Ge CH, Xu WX, Zhan YQ, Li CY, Li W, Wang XH, Wang $\mathrm{ZD}$ and $\mathrm{Yu} \mathrm{M}$. Yang $\mathrm{XM}$. Mice overexpression of human augmenter of liver regeneration (hALR) in male germ cells shows abnormal spermatogenesis and reduced fertility. Endocr. J. 2012; 59:989-99. I Article

163. Zhang $L$, Wang $H$, Yang $Y$, Liu $H$, Zhang $Q$, Xiang $Q$, Ge R, Su $Z$ and Huang $Y$. NGF induces adult stem Leydig cells to proliferate and differentiate during Leydig cell regeneration. Biochem Biophys Res Commun. 2013; 436:300-5. | Article | PubMed

164. Gamwell LF, Collins $O$ and Vanderhyden BC. The mouse ovarian surface epithelium contains a population of LY6A (SCA-1) expressing progenitor cells that are regulated by ovulation-associated factors. Biol Reprod. 2012; 87:80. | Article | PubMed

165. Nakagawa H, Ishizu H, Chinone A, Kobayashi K and Matsumoto $M$. The Dr-nanos gene is essential for germ cell specification in the planarian Dugesia ryukyuensis. Int J Dev Biol. 2012; 56:165-71. | Article | PubMed

166. Willadsen SM. Nuclear transplantation in sheep embryos. Nature. 1986; 320:63-5. | Article | PubMed

167. Willadsen SM. Cloning of sheep and cow embryos. Genome. 1989; 31:956-62. | Article | PubMed

168. Campbell KH, McWhir J, Ritchie WA and Wilmut I. Sheep cloned by nuclear transfer from a cultured cell line. Nature. 1996; 380:64-6. Article I PubMed

169. Gurdon JB. Factors responsible for the abnormal development of embryos obtained by nuclear transplantation in Xenopus laevis. $J$ Embryol Exp Morphol. 1960; 8:327-40. | Article | PubMed

170. Gurdon JB. The developmental capacity of nuclei taken from differentiating endoderm cells of Xenopus laevis. J Embryol Exp Morphol. 1960; 8:505-26. | Article I PubMed

171. Brafman DA. Constructing stem cell microenvironments using bioengineering approaches. Physiol Genomics. 2013; 45:1123-35. I Article I PubMed

172. Issigonis M and Matunis E. The Drosophila BCL6 homolog Ken and Barbie promotes somatic stem cell self-renewal in the testis niche. Dev Biol. 2012; 368:181-92. | Article | PubMed Abstract | PubMed Full Text

173. Toledano H, D'Alterio C, Czech B, Levine E and Jones DL. The let-7-Imp axis regulates ageing of the Drosophila testis stem-cell niche. Nature. 2012; 485:605-10. | Article | PubMed

174. Leatherman JL and Dinardo S. Zfh-1 controls somatic stem cell selfrenewal in the Drosophila testis and nonautonomously influences germline stem cell self-renewal. Cell Stem Cell. 2008; 3:44-54. | Article | PubMed Abstract | PubMed Full Text

175. Arbouzova NI, Bach EA and Zeidler MP. Ken \& barbie selectively regulates the expression of a subset of Jak/STAT pathway target genes. Curr Biol. 2006; 16:80-8. | Article | PubMed

176. Flaherty MS, Salis P, Evans CJ, Ekas LA, Marouf A, Zavadil J, Banerjee U and Bach EA. chinmo is a functional effector of the JAK/STAT pathway that regulates eye development, tumor formation, and stem cell selfrenewal in Drosophila. Dev Cell. 2010; 18:556-68.

177. White YA, Woods DC, Takai Y, Ishihara O, Seki H and Tilly JL. Oocyte formation by mitotically active germ cells purified from ovaries of reproductive-age women. Nat Med. 2012; 18:413-21. | Article | PubMed Abstract | PubMed Full Text

178. Zhao Y. Stem cell educator therapy and induction of immune balance. Curr Diab Rep. 2012; 12:517-23. I Article I PubMed

179. Ichiryu N and Fairchild PJ. Immune privilege of stem cells. Methods $\mathrm{Mol}$ Biol. 2013; 1029:1-16. | Article | PubMed

180. Dirice E, Kahraman S, Jiang W, El Ouaamari A, De Jesus DF, Teo AK, Hu J, Kawamori D, Gaglia JL, Mathis D and Kulkarni RN. Soluble factors secreted by T cells promote beta-cell proliferation. Diabetes. 2014; 63:188-202. | Article | PubMed Abstract | PubMed Full Text

181. Lin Z, Fateh A, Salem DM and Intini G. Periosteum: biology and applications in craniofacial bone regeneration. J Dent Res. 2014; 93:109-16. | Article | PubMed Abstract | PubMed Full Text
182. Wan AC and Tai BC. CHITIN--a promising biomaterial for tissue engineering and stem cell technologies. Biotechnol Adv. 2013; 31:1776-85. | Article | PubMed

183. Lim ML, Jungebluth $P$, Ajalloueian F, Friedrich LH, Gilevich I, Grinnemo KH, Gubareva E, Haag JC, Lemon G, Sjoqvist S, Caplan AL and Macchiarini P. Whole organ and tissue reconstruction in thoracic regenerative surgery. Mayo Clin Proc. 2013; 88:1151-66. | Article | PubMed

184. Scotti C, Hirschmann MT, Antinolfi P, Martin I and Peretti GM. Meniscus repair and regeneration: review on current methods and research potential. Eur Cell Mater. 2013; 26:150-70. | Article | PubMed

185. Clark A. Human somatic cell nuclear transfer: a scientist's perspective. Mol Reprod Dev. 2013; 80. | Article I PubMed

186. Yamanaka S. Induced pluripotent stem cells: past, present, and future. Cell Stem Cell. 2012; 10:678-84. I Article I PubMed

187. Wu DC, Boyd AS and Wood KJ. Embryonic stem cell transplantation: potential applicability in cell replacement therapy and regenerative medicine. Front Biosci. 2007; 12:4525-35. | PubMed

\section{Citation:}

Upadhyay RK. Role of regeneration in tissue repairing and therapies. J Regen Med Tissue Eng. 2015; 4:1.

http://dx.doi.org/10.7243/2050-1218-4-1 